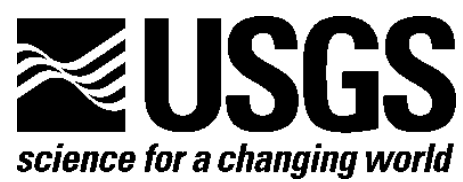

Prepared in Cooperation with Universidad Autónoma de Baja California and Centro de Investigación Científica y de Educación Superior de Ensenada

\title{
Geophysical Data Collected During the 2014 Minute 319 Pulse Flow on the Colorado River Below Morelos Dam, United States and Mexico
}

By Jeffrey R. Kennedy, James B. Callegary, Jamie P. Macy, Jaime Reyes-Lopez, and Marco Pérez-Flores

Open-File Report 2017-1050

U.S. Department of the Interior

U.S. Geological Survey 


\section{U.S. Department of the Interior \\ RYAN K. ZINKE, Secretary}

\section{U.S. Geological Survey \\ William H. Werkheiser, Acting Director}

U.S. Geological Survey, Reston, Virginia: 2017

For more information on the USGS—-the Federal source for science about the Earth, its natural and living resources, natural hazards, and the environment-visit http://www.usgs.gov/ or call 1-888-ASK-USGS (1-888-275-8747).

For an overview of USGS information products, including maps, imagery, and publications, visit http://www.usgs.gov/pubprod/.

Any use of trade, firm, or product names is for descriptive purposes only and does not imply endorsement by the U.S. Government.

Although this information product, for the most part, is in the public domain, it also may contain copyrighted materials as noted in the text. Permission to reproduce copyrighted items must be secured from the copyright owner.

Suggested citation:

Kennedy, J.R., Callegary, J.B., Macy, J.P., Reyes-Lopez, J., Pérez-Flores, M., 2017, Geophysical data collected during the 2014 minute 319 pulse flow on the Colorado River below Morelos Dam, United States and Mexico: U.S. Geological Survey Open-File Report 2017-1050, 48 p., https://doi.org/10.3133/ofr20171050. 


\section{Acknowledgments}

Many parties contributed to this data-collection effort. The overall project was administered by the International Boundary and Water Commission and the Comisión Internacional de Límites y Aguas. Extensive support was provided by the U.S. Bureau of Reclamation, the U.S. Geological Survey Arizona Water Science Center's Yuma Field Office, and the U.S. Geological Survey Southwest Region office. Jeff Milliken at the U.S. Bureau of Reclamation was instrumental in obtaining the lidar and inundation data used in the analysis of gravity data. Geoff DeBenedetto, Matt Garcia, Eloise Kendy, Colin Kikuchi, Kristen Landrum, Michael Landrum, Fernando Herrera, Agustín Oropeza, and Gricel Xancal assisted with fieldwork. Additional volunteer assistance from The Nature Conservancy is gratefully acknowledged. 


\section{Contents}

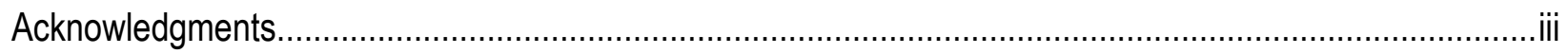

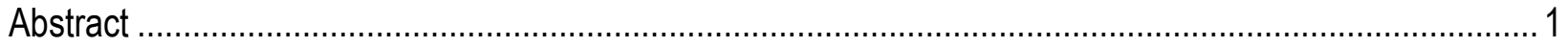

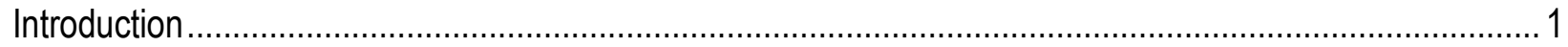

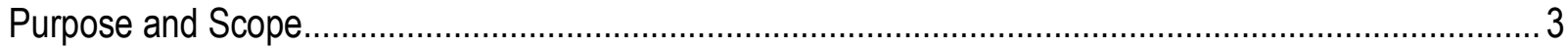

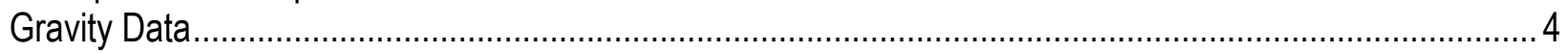

Absolute-Gravity Measurements ............................................................................................

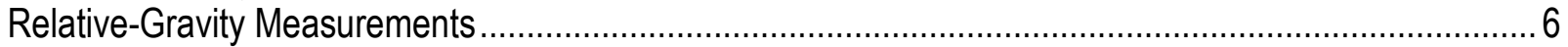

Direct Gravitational Attraction of In-Channel Water....................................................................

Least-squares Network Adjustment .............................................................................................. 8

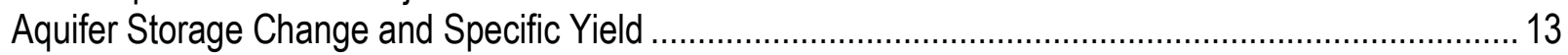

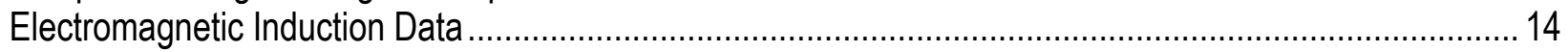

Transect Data Description and Relation to Site Characteristics ...................................................... 16

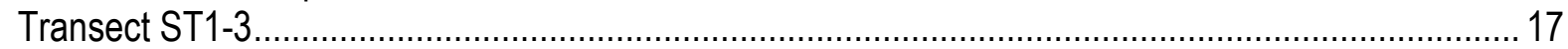

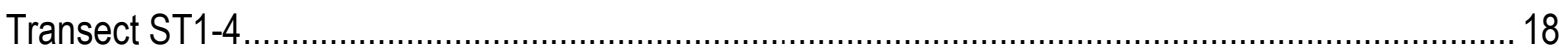

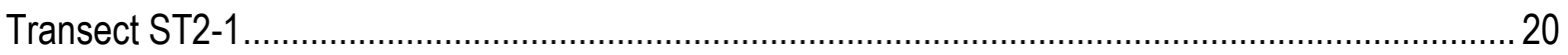

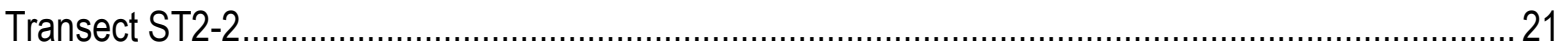

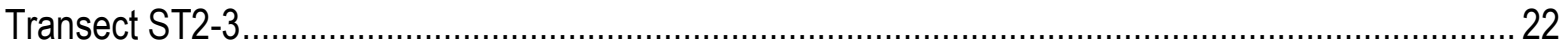

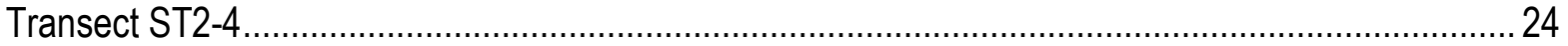

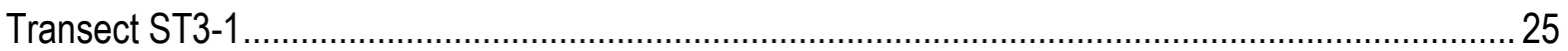

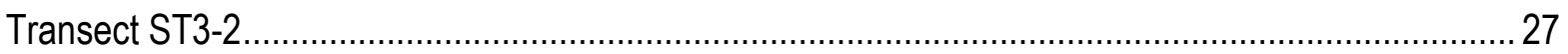

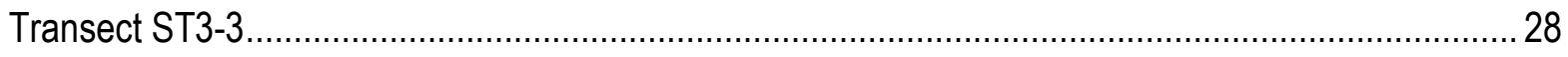

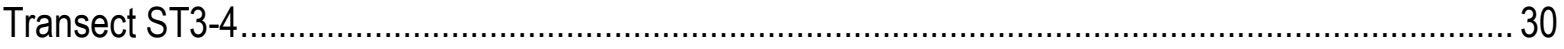

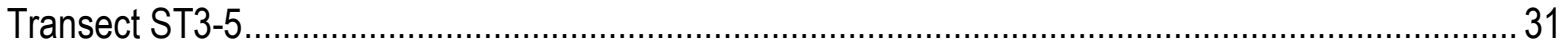

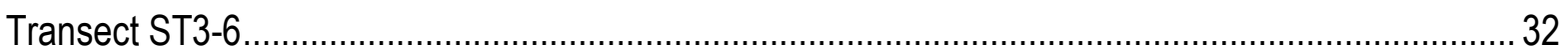

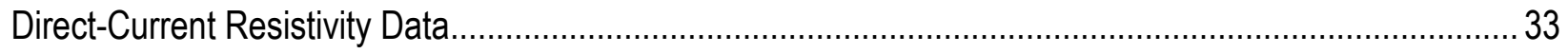

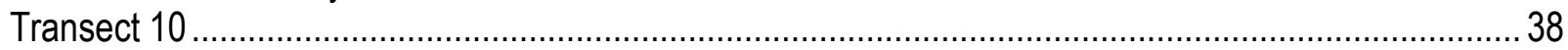

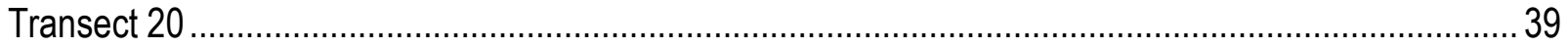

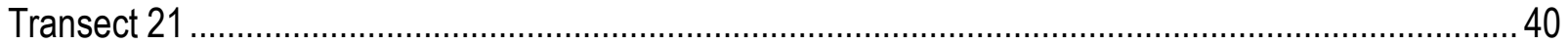

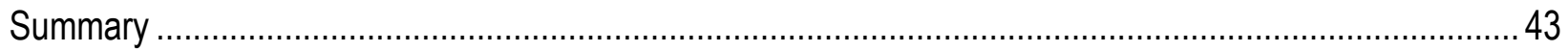

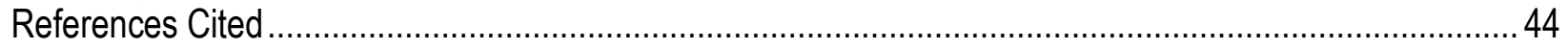

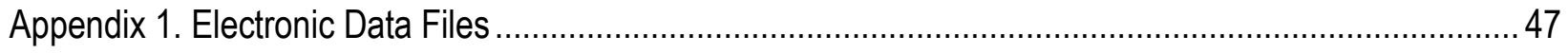

\section{Figures}

1. Map showing the study area and general locations of geophysical data collection ..........................

2. Hydrograph of the Minute 319 pulse flow at two delivery points and two downstream locations ...... 4

3. Photographs showing gravity stations constructed to monitor the Minute 319 pulse flow.................5

4. Photograph showing a relative-gravity observation at station Min319-21 …...............................

5. Map showing change in aquifer storage derived from gravity data, from March 11 to April 1, 2014, in the southern limitrophe reach of the Colorado River, United States-Mexico Border .................. 10

6. Map showing change in aquifer storage derived from gravity data, from April 1 to 20, 2014, in the southern limitrophe reach of the Colorado River, United States-Mexico Border .......................... 11

7. Map showing change in aquifer storage derived from gravity data, from March 11 to April 20, 2014, in the southern limitrophe reach of the Colorado River, United States-Mexico Border .................. 12 
8. Scatterplot showing specific yield calculation for four locations in the southern limitrophe reach of the Colorado River.

9. Diagram indicating orientation of transmitter and receiver coils relative to each other, to the soil surface, and to transects

10. Photograph showing geophysicists preparing to make an electromagnetic induction measurement using an EM-38 instrument......................................................................................... 16

11. Transect ST1-3 location and data, Colorado River, United States-Mexico Border.......................... 18

12. Transect ST1-4 location and data, Colorado River, United States-Mexico Border........................ 19

13. Transect ST2-1 location and data, Colorado River, United States-Mexico Border......................... 20

14. Transect ST2-2 location and data, Colorado River, United States-Mexico Border......................... 22

15. Transect ST2-3 location and data, Colorado River, United States-Mexico Border......................... 23

16. Transect ST2-4 location and data, Colorado River, United States-Mexico Border.......................... 25

17. Transect ST3-1 location and data, Colorado River, United States-Mexico Border.........................26

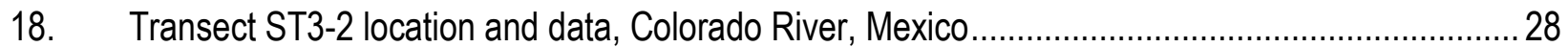

19. Transect ST3-3 location and data, Colorado River, Mexico .......................................................... 29

20. Transect ST3-4 location and data, Colorado River, Mexico ........................................................ 30

21. Transect ST3-5 location and data, Colorado River, Mexico ......................................................... 32

22. Transect ST3-6 location and data, Colorado River, Mexico ........................................................ 33

23. Dipole-dipole resistivity field setup and survey................................................................ 35

24. Map showing the location of the U.S. Geological Survey direct-current resistivity Transect 10 and nearby piezometers and gravity stations, Colorado River, Arizona.............................................. 37

25. Map showing the location of the UABC and CICESE direct-current resistivity Transect 20 and Transect 21, Colorado River, Mexico

26. Cross sections showing apparent resistivity inversion of direct-current resistivity data at Transect 10, Colorado River, Arizona

27. Cross sections showing apparent resistivity inversion of direct-current resistivity data at Transect 20, Colorado River, Mexico

28. Cross sections showing apparent resistivity inversion of direct-current resistivity data at Transect 21

Colorado River, Mexico

\section{Tables}

1. Network adjustment statistics. 


\section{Conversion Factors}

\begin{tabular}{|c|c|c|}
\hline Multiply & By & To obtain \\
\hline \multicolumn{3}{|c|}{ Length } \\
\hline centimeter $(\mathrm{cm})$ & 0.3937 & inch (in.) \\
\hline meter $(\mathrm{m})$ & 3.281 & foot (ft) \\
\hline kilometer $(\mathrm{km})$ & 0.6214 & mile (mi) \\
\hline meter $(\mathrm{m})$ & 1.094 & yard (yd) \\
\hline \multicolumn{3}{|c|}{ Volume } \\
\hline cubic meter $\left(\mathrm{m}^{3}\right)$ & 6.290 & barrel (petroleum, 1 barrel = 42 gal) \\
\hline cubic meter $\left(\mathrm{m}^{3}\right)$ & 264.2 & gallon (gal) \\
\hline cubic meter $\left(\mathrm{m}^{3}\right)$ & 0.0002642 & million gallons (Mgal) \\
\hline cubic meter $\left(\mathrm{m}^{3}\right)$ & 35.31 & cubic foot $\left(\mathrm{ft}^{3}\right)$ \\
\hline cubic meter $\left(\mathrm{m}^{3}\right)$ & 1.308 & cubic yard $\left(\mathrm{yd}^{3}\right)$ \\
\hline cubic meter $\left(\mathrm{m}^{3}\right)$ & 0.0008107 & acre-foot (acre-ft) \\
\hline \multicolumn{3}{|c|}{ Acceleration } \\
\hline microgal $(\mu \mathrm{Gal})$ & 10 & nanometer per second squared $\left(\mathrm{nm} / \mathrm{s}^{2}\right)$ \\
\hline microgal $(\mu \mathrm{Gal})$ & $0.328 \times 10^{-9}$ & feet per second squared $\left(\mathrm{ft} / \mathrm{s}^{2}\right)$ \\
\hline
\end{tabular}

\section{Datum}

Vertical coordinate information is referenced to the North American Vertical Datum of 1988 (NAVD 88).

Horizontal coordinate information is referenced to the North American Datum of 1983 (2011) epoch 2010.00 (NAD 83). 


\section{Abbreviations}

CICESE Centro de Investigación Científica y de Educación Superior de Ensenada

DC direct current

EMI electromagnetic induction

GPS global positioning system

HCP horizontal coplanar orientation

ICS intercoil spacing

$\mathrm{mA} \quad$ milliamps

masl meters above sea level

mbar millibar

$\mathrm{mS} \quad$ millisiemens

$\mu$ Gal microgal $\left(1 \times 10^{-9} \mathrm{~m} / \mathrm{s}^{2}\right)$

ohm-m ohm-meters

UABC Universidad Autónoma de Baja California

USGS U.S. Geological Survey

VCP vertical coplanar orientation

$\sigma_{\mathrm{a}} \quad$ apparent electrical conductivity 


\title{
Geophysical Data Collected During the 2014 Minute 319 Pulse Flow on the Colorado River Below Morelos Dam, United States and Mexico
}

\author{
By Jeffrey R. Kennedy, ${ }^{1}$ James B. Callegary, ${ }^{1}$ Jamie P. Macy, ${ }^{1}$ Jaime Reyes-Lopez, ${ }^{2}$ and Marco \\ Pérez-Flores ${ }^{3}$
}

\begin{abstract}
Geophysical methods were used to monitor infiltration during a water release, referred to as a "pulse flow," in the Colorado River delta in March and April 2014. The pulse flow was enabled by Minute 319 of the 1944 United States-Mexico Treaty concerning water of the Colorado River. Fieldwork was carried out by the U.S. Geological Survey and the Centro de Investigación Científica y de Educación Superior de Ensenada as part of a binational effort to monitor the hydrologic effects of the pulse flow along the limitrophe (border) reach of the Colorado River and into Mexico. Repeat microgravity measurements were made at 25 locations in the southern limitrophe reach to quantify aquifer storage change during the pulse flow. Observed increases in storage along the river were greater with distance to the south, and the amount of storage change decreased away from the river channel. Gravity data at four monitoring well sites indicate specific yield equal to $0.32 \pm 0.05$. Electromagnetic induction methods were used at 12 transects in the limitrophe reach of the river along the United StatesMexico border, and farther south into Mexico. These data, which are sensitive to variation in soil texture and water content, suggest relatively homogeneous conditions. Repeat direct-current resistivity measurements were collected at two locations to monitor groundwater elevation. Results indicate rapid groundwater-level rise during the pulse flow in the limitrophe reach and smaller variation at a more southern transect. Together, these data are useful for hydrogeologic characterization and hydrologic model development. Electronic data files are provided in the accompanying data release (Kennedy and others, 2016a).
\end{abstract}

\section{Introduction}

In spring 2014, about 130 million cubic meters of water, as agreed upon in Minute 319 of the 1944 United States-Mexico Treaty, was released into the lower Colorado River channel with the purpose of inundating the active channel and some floodplain areas of the modern delta for ecological restoration and habitat development. In support of Minute 319, the U.S. Geological

\footnotetext{
${ }^{1}$ U.S. Geological Survey.

${ }^{2}$ Universidad Autónoma de Baja California.

${ }^{3}$ Centro de Investigación Científica y de Educación Superior de Ensenada.
} 
Survey (USGS), the Universidad Autónoma de Baja California (UABC), and the Centro de Investigación Científica y de Educación Superior de Ensenada (CICESE) collected geophysical data before, during, and after the pulse flow.

Three geophysical methods were used: time-lapse gravity, electromagnetic induction (EMI), and direct-current (DC) resistivity. Gravity data provided information about the spatial distribution and magnitude of aquifer storage change. Gravity data were collected using absolute- and relative-gravity meters at a network of 25 stations in the southern limitrophe reach of the Colorado River (fig. 1). A total of three surveys were completed: (1) before the pulse flow, (2) 1 week into the pulse flow, and (3) 4 weeks into the pulse flow. Electromagnetic induction data were collected at 12 transects throughout the study area (fig. 1) prior to the pulse flow. DC resistivity data were collected at three transects (fig. 1) during the first week of the pulse flow. The USGS, UABC, and CICESE collected EMI and DC resistivity data, at different transects, using identical equipment and methods.

The study area encompasses the Colorado River in the upper part of its delta in far southwestern Arizona and northern Baja California and Sonora in Mexico (fig. 1). In this reach, extensive irrigated agriculture surrounds the river on both sides, which is constrained within manmade levees throughout most of the area shown in figure 1. Upstream diversions, the southernmost (downstream) of which is Morelos Dam, result in a dry river channel through most of the study area. In the northern part of the study area, the river forms the international boundary between the United States and Mexico. Because of this, prior to the pulse flow scientists from both countries worked to establish common standards, and during the pulse flow they carried out fieldwork across the border to collect a cohesive dataset.

Sediment in the delta was deposited from transgressions of the Gulf of California from the south, from fluvial deposits of the Colorado River, and, to a lesser extent, from alluvial deposits that form the basin margins (Olmsted and others, 1973). Total sediment thickness in the basin center is greater than $3,000 \mathrm{~m}$, and sediment thins to zero at the basin margins. The uppermost deposits that constitute the part of the aquifer that interacts with surface water, and are therefore the focus of this paper, are predominantly discontinuous sand, silt, and clay deposits dating to the Pleistocene and Holocene (Olmsted and others, 1973; Dickinson and others, 2006).

The pulse-flow release from Morelos Dam spanned 5 weeks in March through May 2014 (fig. 2). In normal, non-flood conditions of the past several years (and prior to the pulse flow), the Colorado River is perennial from Morelos Dam south for about $20 \mathrm{~km}$ (the extent of the four most northerly electromagnetic induction stations in fig. 1). Downstream of this point, for about $40 \mathrm{~km}$, the river channel is generally dry with little or no surface water. Perennial flow returns farther south in Mexico, near the southernmost electromagnetic induction station (fig. 1). Additional water was delivered downstream by irrigation canals; these deliveries influenced results at the southern DC resistivity transects but not at gravity stations or the DC resistivity transect in the southern limitrophe reach. Much of the water (about 40 percent) infiltrated between Morelos Dam and the Southerly International Boundary, which marks the southern end of the limitrophe reach. By May 2014, the limitrophe reach had returned largely to pre-pulseflow conditions, with a largely dry channel in the southern part.

Several papers and reports provide additional information about the pulse flow. An overview and general results are available from the International Boundary and Water Commission (IBWC) $(2014,2016)$. The progression of the wetting front and inundated area analysis are reported in Nelson and others (2016). The groundwater response to the pulse flow is 
reported in Kennedy and others (2016b), the geomorphic response is reported in Mueller and others (2016), and the vegetation response is reported in Jarchow and others (2016).

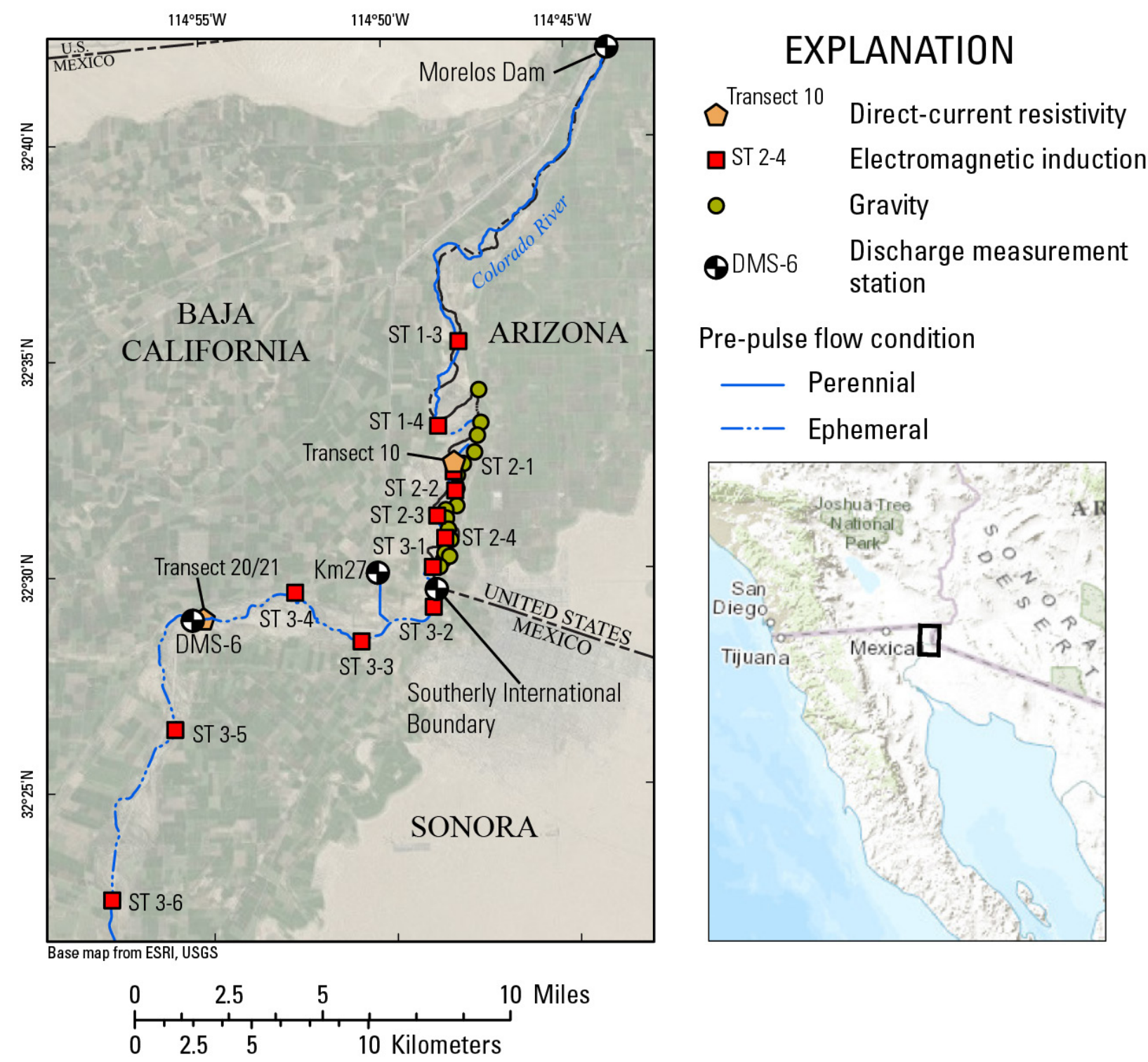

Figure 1. Map showing the study area and general locations of geophysical data collection.

\section{Purpose and Scope}

This report describes gravity, EMI, and DC resistivity data collected in March and April 2014 during the Minute 319 pulse flow in the lower Colorado River, in Arizona and in Baja California, Mexico. Limited data interpretation is provided where appropriate. Data files are provided online in the accompanying data release (Kennedy and others, 2016a). The purpose of this data collection effort was to characterize the subsurface hydrogeology and gain information about the groundwater response to the Minute 319 pulse flow. Gravity stations were located on the floodplain along the southern $8 \mathrm{~km}$ of the limitrophe reach where infiltration losses were expected to be highest. Gravity-change data are associated with changes in aquifer storage. At 
four gravity stations, specific yield was calculated from gravity change and groundwater-level change at co-located piezometers. EMI and DC resistivity measure the electrical characteristics of the subsurface materials, which are related to rock type, soil texture, soil water content, and salinity. EMI data were collected prior to the pulse flow at 5-m intervals along 12 transects in the United States and Mexico. Transects crossed the river channel and extended onto the floodplain on each side. DC resistivity data were collected at three transects. In the United States, one transect was located parallel to the channel in the southern limitrophe reach nearby a streamgaging station. In Mexico, two transects were measured, one parallel and one perpendicular to the channel. Measurement positions for all three geophysical methods were determined using differential global positioning system (GPS) data.

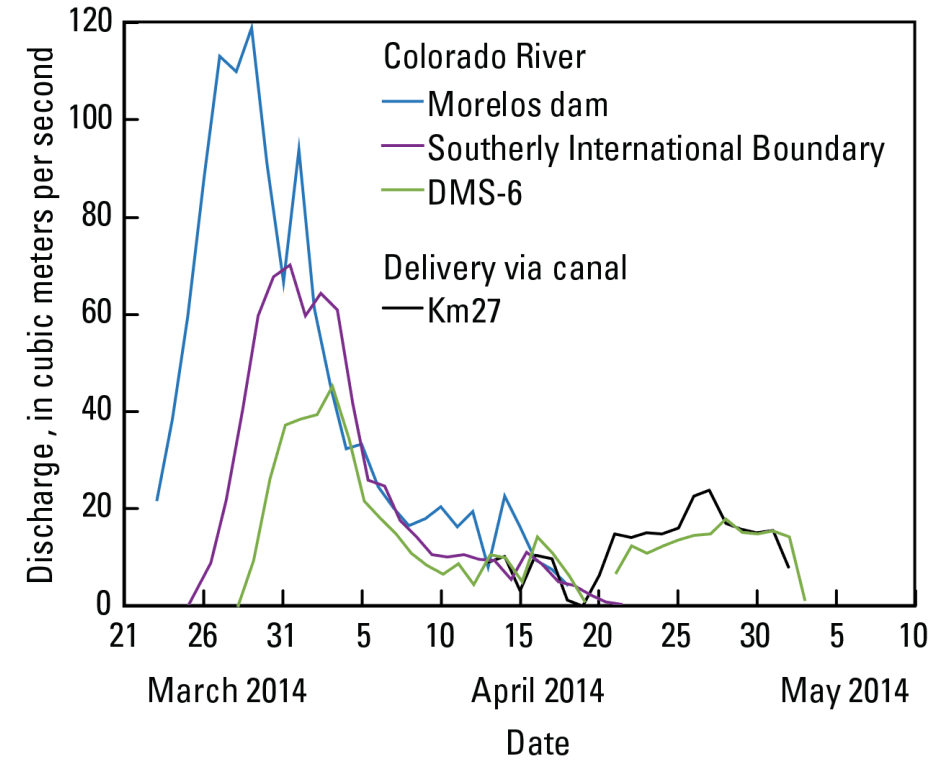

Figure 2. Hydrograph of the Minute 319 pulse flow at two delivery points (Morelos Dam and Km27) and at two downstream locations (Southerly International Boundary and DMS-6).

\section{Gravity Data}

Gravity data are measurements of the vertical acceleration owing to the Earth's gravitational potential (henceforth, gravity). Gravity data were collected using both absolute- and relative-gravity meters. Absolute-gravity meters measure gravity directly by measuring the acceleration of a free-falling test mass. Relative-gravity meters measure only the relative difference in gravity between stations, and must be combined with absolute-gravity data to determine the actual gravity value at a station (alternatively, measurements can be made relative to a gravitationally stable benchmark). Absolute- and relative-gravity measurements are analogous to fixed benchmarks and relative height differences, respectively, in leveling surveys; absolute-gravity measurements establish the datum for a particular survey (that is, they serve as benchmarks), whereas relative differences are observed between the absolute stations and the remaining stations. In most surveys, including this one, absolute-gravity measurements are made at a relatively small number of stations, and relative-gravity differences are observed between the absolute-gravity stations and the remaining stations. As with leveling, a least-squares network adjustment is performed to combine all of the data and derive final values for each station, while accounting for uncertainty in the measurements, and accommodating redundant measurements. 
Twenty-five gravity stations were constructed along an approximately 8 -km reach of the Colorado River (fig. 1). Four of these stations were constructed to accommodate an absolutegravity meter, and they each consisted of a $4.9-\mathrm{m}$ to $6.1-\mathrm{m}$ survey rod, driven to refusal, surrounded by, but isolated from, a $30.5-\mathrm{cm}$ concrete form (fig. $3 \mathrm{~A}$ ). Isolation of the concrete form from the survey rod allows the form to move with soil shrink and swell while the rod is anchored to deeper soil that should be less susceptible to soil shrink and swell. The absolutegravity meter was set up on the concrete form and bricks in the surrounding sand (fig. $3 B$ ). The height of the absolute-gravity meter was measured relative to the top of the survey rod. Relativegravity stations were constructed at the remaining 21 stations using 1-m long "Feno"-type survey rods, which, after installing flush with the land surface, have three prongs at the lower end which are extended into the subsurface (fig. $3 \mathrm{C}$ ). The survey rod serves as a vertically stable monument for the reference leg of a relative-gravity meter. A $41-\mathrm{cm}$ square, $5-\mathrm{cm}$ thick concrete paver was installed adjacent to the survey rod; the other two legs of the relative-gravity meter were located on the paver (fig. 3C). All gravity stations were located using differential GPS. Careful inspection and photographs taken during each site visit were used to assess any disturbance or potential for vertical movement between measurements. Gravity data were collected during three field campaigns in 2014: March 11-19, April 1-4, and April 20-24. Absolute-gravity data were collected at the both the start and end of each campaign.
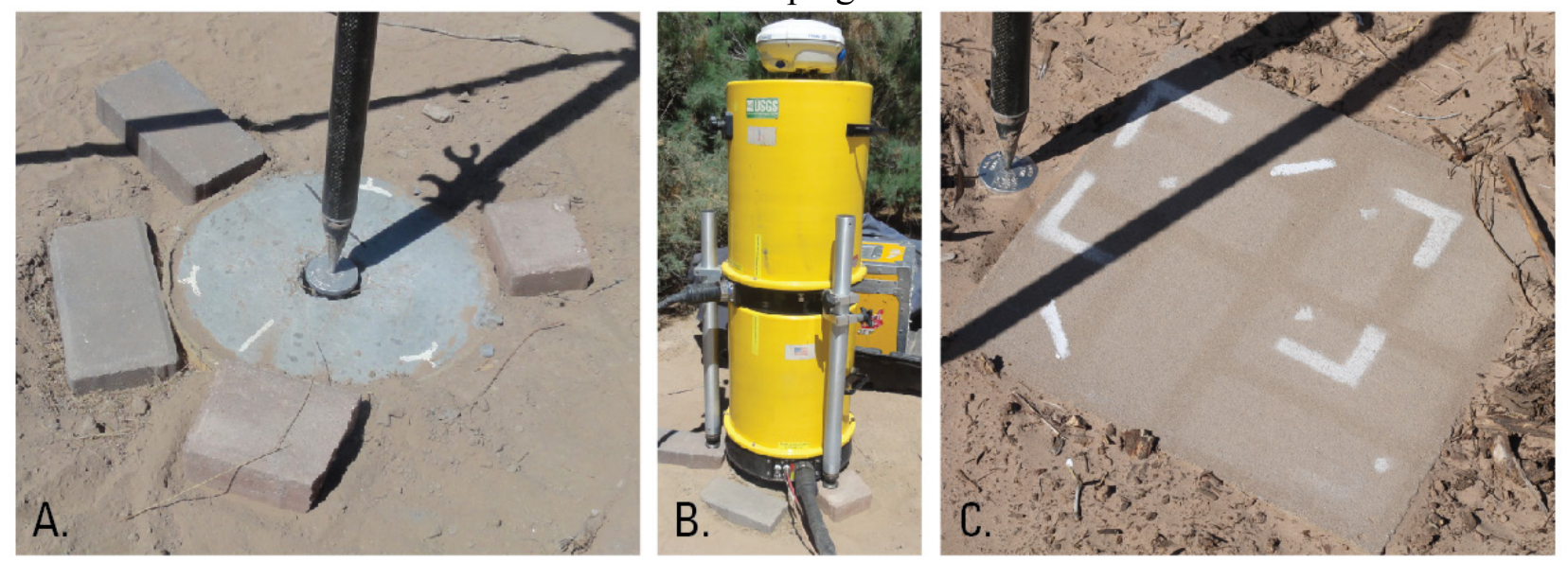

Figure 3. Photographs showing gravity stations constructed to monitor the Minute 319 pulse flow. A, Absolute-gravity station with global positioning system (GPS) tripod located on isolated survey rod, surrounded by concrete platform and bricks where an absolute-gravity meter is set up. B, A-10 absolutegravity meter setup on a station. $C$, Survey rod and concrete paver installed as a temporary relative-gravity meter platform. GPS tripod is on the survey mark where the gravity meter reference leg is positioned.

\section{Absolute-Gravity Measurements}

Absolute-gravity data were collected at four stations (fig. 1) using a Micro-g Lacoste, Inc., A-10 absolute-gravity meter. The absolute-gravity meter uses a length scale determined by a laser interferometer and a time scale determined by a rubidium oscillator. A spring mechanism isolates the interferometer from long-period seismic noise. Each measurement consists of between 720 and 1,200 drops of a free-falling test mass, collected in sets of 120 drops, over a 15to 30-minute period. In general, absolute-gravity measurements were relatively noisy compared to other project areas (for example, Kennedy, 2015, Kennedy and others, 2015), which we attribute to the stations being installed in unconsolidated sand. Nonetheless, given the large magnitude of gravity change, the data were considered usable for their stated purpose. 
Absolute-gravity observations for hydrology require several corrections including for deformation owing to Earth tides, variations in ocean loading on the continent, accelerations owing to polar motion (long-period Earth wobble), and gravitational effects of atmospheric mass (Torge, 1989). Earth-tide corrections (to account for gravity changes caused by the periodic elastic deformation of the Earth) for absolute-gravity measurements were determined using the ETGTAB model with the default wave groups in the Micro-g Lacoste, Inc. software (http://www.microglacoste.com/). Ocean-loading corrections (to account for gravity changes caused by surface-loading changes induced by the oceans) were determined using the finite element solution tide model FES2004, produced by Laboratoire d'Etudes en Géophysique et Océanographie Spatiales (http://www.legos.obs-mip.fr/) and Collecte Localisation Satellites' Space Oceanography Division and distributed by AVISO (Archiving, Validation and Interpretation of Satellite Oceanographic Data), with support from Centre National d'Etudes Spatiales (http://www.aviso.altimetry.fr/). Polar motion corrections were determined using coordinates provided by the U.S. Naval Observatory (http://toshi.nofs.navy.mil/). The barometric-pressure correction was calculated using measured barometric pressure and an admittance factor of 0.3 microgal per millibar ( $\mu \mathrm{Gal} / \mathrm{mbar})$.

Absolute-gravity meters use the local vertical-gravity gradient to calculate a gravity value from observed interferometry data, and to transfer gravity values from the instrument height to the survey mark. Local gradients may differ from the free-air gradient owing to local topography and variation in subsurface density. We did not measure vertical gradients as part of this survey because of the flat terrain, homogeneous subsurface inferred from EMI data, and limited time available for fieldwork. Instead we applied a standard vertical gradient, $-3 \mu \mathrm{Gal} / \mathrm{cm}$, at each absolute-gravity station.

\section{Relative-Gravity Measurements}

Relative-gravity observations were made at all 25 stations (fig. 1) using a ZLS Corporation, Inc., Burris gravity meter (fig. 4). Relative-gravity meters are hindered by lowfrequency instrument "drift," by which the measured value at any given station changes continually (this instrumental effect is independent of other sources of gravity change, such as Earth tides). Repeat measurements at one or more stations are necessary to identify and remove this instrumental drift. For the surveys included in this report, stations were generally observed in the order A-B-C-B-A-C, where each letter represents a different station; each time a repeat measurement is made at a station an estimate of instrument drift is obtained. If instrumental drift is considered continuous over some period (typically 1 day) a curve, or model, can be fitted to the individual estimates of instrumental drift. Then, drift-corrected values can be calculated by subtracting the modeled drift from the observed values. Relative-gravity meter precision, estimated qualitatively, was similar to relative-gravity surveys in other project areas.

Each relative-gravity observation is accompanied by an estimate of standard deviation provided by the relative-gravity meter. Only data with standard deviation less than $6 \mu \mathrm{Gal}$ were recorded. Because the basic observation is the difference in gravity between two stations, and the measurement at each station is considered independent, the uncertainty (standard deviation) of the differenced measurement is obtained by taking the square root of the sum of squares:

$$
\sigma_{d g}=\sqrt{\sigma_{A}^{2}+\sigma_{B}^{2}}+\sigma_{i}
$$

where $\sigma_{d g}$ $\sigma_{A}^{2}$ and $\sigma_{B}^{2}$

is the standard deviation of the differenced measurement, are the standard deviations at station 1 and station 2, respectively, and 
$\sigma_{i} \quad$ is additional instrument uncertainty.

The station standard deviations, $\sigma_{A}^{2}$ and $\sigma_{B}^{2}$, are estimated to be the standard deviation of several observations recorded over about 1 minute at a particular station. Because these observations are generally stable, and do not account for uncertainty in the drift correction, the resultant standard deviations are generally lower than the actual measurement error; a more realistic uncertainty estimate is obtained by including $\sigma_{i}$ equal to $2 \mu \mathrm{Gal}$. The accuracy of the $\sigma_{d g}$ estimate is evaluated during the network adjustment as described in the Least-Squares Network Adjustment section of this report. When performing the network adjustment, $\sigma_{d g}$ is used to weight each observation.

\section{Direct Gravitational Attraction of In-Channel Water}

The measured change in gravity at each station reflects all sources of mass change. Some of these, such as Earth tides and ocean loading, are subtracted during data processing. An additional source of mass change is freestanding water in the river channel. To determine the amount of water stored in the subsurface, it is necessary to remove the direct gravitational attraction of the water in the channel.

The gravitational attraction of in-channel water was removed by considering the measured water surface elevation (stage) relative to the surrounding topography derived from airborne light detection and ranging (lidar). Lidar data were obtained prior to the pulse flow when the channel was dry. The volume between the channel bottom and the water surface was discretized into cubes $1 \times 1 \mathrm{~m}$ in the horizontal direction, and with height equal to the distance between the land surface and the water surface. The gravitational attraction of each cube relative to each individual gravity station is calculated using the Nagy formula for rectangular prisms (Nagy, 1966). Because the gravity meters used are sensitive only to the vertical acceleration of gravity, and in-channel water is at close to the same elevation as the gravity stations, the effect decreases rapidly with distance from the channel. Only three stations had corrections larger than $1 \mu \mathrm{Gal}$; the largest correction is $12.1 \mu \mathrm{Gal}$ at station Min319-21. Because the variation in the correction for the direct gravitational attraction is small (less than $1 \mu \mathrm{Gal}$ ) during any one week of surveys, the final gravity values were corrected after doing the network adjustment.

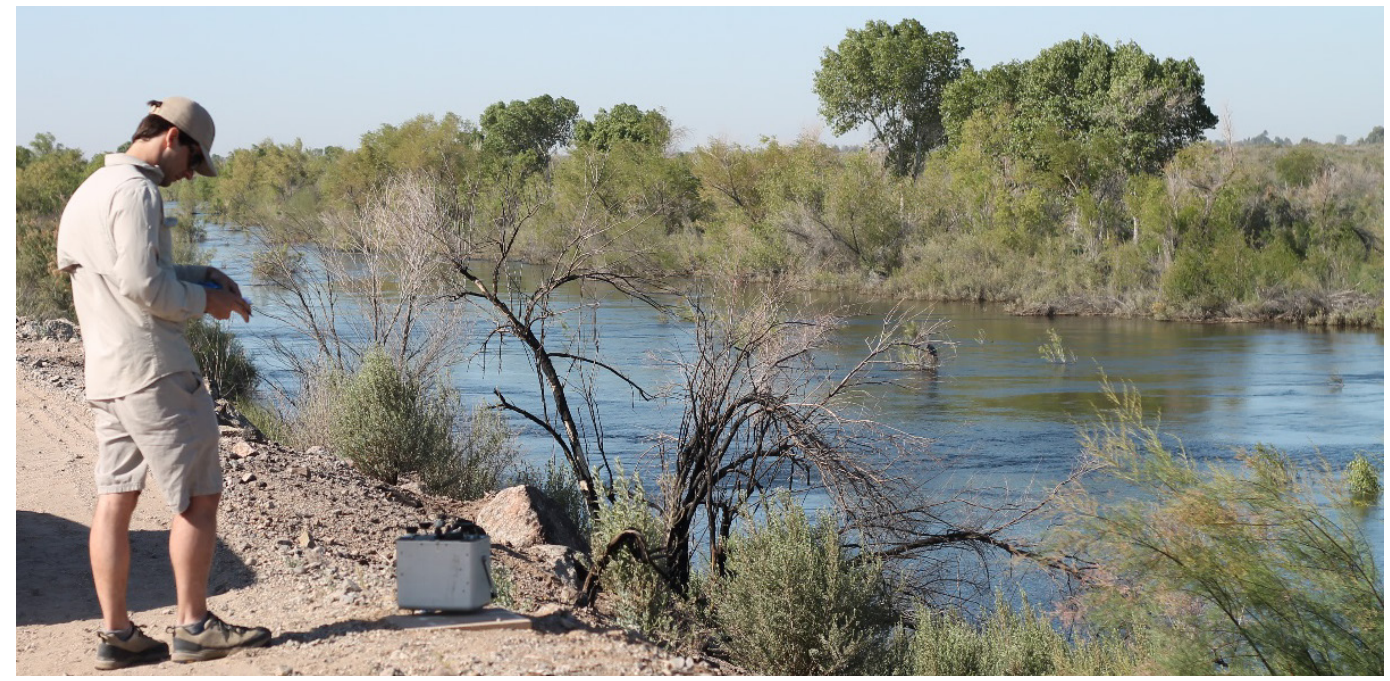

Figure 4. Photograph showing a relative-gravity observation at station Min319-21. The direct gravitational attraction of water in the channel at this station at this time is 12.1 microgals. 


\section{Least-squares Network Adjustment}

Least-squares network adjustment, a common method for combining survey measurements of all kinds, describes a system of linear equations solved to arrive at a single value, such as elevation or gravity, for each station (Strang and Borre, 1997). Network adjustment is the method by which measurement error is distributed across a network. For example, if measurement differences (for example, height or gravity differences) are observed in a loop (from station A to station B, station B to station C, and station C back to station A), there will be some misclosure - the observations will not sum to exactly zero. If the uncertainty of each individual observation is identical, then the misclosure can be distributed evenly between all of the observed gravity differences. More commonly some observations are better than others, and therefore assigned greater weight in the network adjustment.

The basic network-adjustment equation is as follows:

$$
\Delta g=g_{2}-g_{1}+e
$$

where $\Delta g \quad$ is the observed gravity difference between the observed values $g_{1}$ and $g_{2}$, and is the error between the observed and predicted value.

Least-squares network adjustment minimizes $e$ by finding the set of gravity values, for all stations, that minimizes the squared error between the observed and network-adjusted gravity differences. Unlike some network-adjustment equations (Hwang and others, 2002), the equation above does not account for instrument drift or circular (screw) error, although a first-order linear term (not shown) is included to estimate the calibration factor between the relative-gravity meter and absolute-gravity meter used in the study. We correct for instrument drift prior to performing the network adjustment by fitting a polynomial or LOWESS (locally weighted scatterplot smooth) model to repeat gravity observations at a single station, which provide point estimates of drift (Kennedy and Ferré, 2016). This allows for a non-linear drift model and is generally more flexible than including a drift term in the network adjustment. Circular error describes error introduced as a result of imperfect calibration of the gravity meter dial mechanism. In this study, circular error can be ignored because the Burris relative-gravity meter is equipped with an electronic feedback system with a relatively large range, and therefore all stations were observed at the same dial setting.

Network-adjustment results are shown in table 1. For each survey, it was necessary to remove observations considered outliers from the adjustment. This was accomplished by iteratively removing observations with residuals (that is, large differences between the observed and adjusted gravity differences) greater than $\pm 10 \mu \mathrm{Gal}$. Outliers may be caused by poor readings, large drift, or poorly modeled drift or offsets (tares) during initial data processing. Outliers are common in relative-gravity data and removing some observations is typically necessary to achieve good network-adjustment results (Hwang and others, 2002; Touati and others, 2010).

In addition to removing outliers, the estimated uncertainty of the observations is adjusted iteratively during the network adjustment. The network adjustment provides an independent estimate of the observation uncertainty based on the size of the residuals, or in other words, how well the measurements "fit together". The network-adjusted uncertainty is compared to the original uncertainty estimates using the squared root of a posterior variance of unit weight (also known as the reference factor). A posterior values close to one indicate the two uncertainty estimates are in good agreement. The network-adjustment results can be evaluated by using a chi-square test to determine if the reference factor is significantly different than 1, based on the 
number of observations and degrees of freedom in the network. Observational outliers were eliminated and the standard deviation multiplier was adjusted until each of the surveys achieved an acceptable chi-square test statistic at the 95-percent confidence level. For the first and last surveys, it was necessary to multiply the original standard deviation estimates by a factor of 1.3 to achieve a suitable reference factor (table 1).

The relative-gravity meter calibration factor calculated during the network adjustment was less than one standard deviation away from 1 (table 1), indicating good agreement between the relative-gravity differences and the absolute-gravity observations.

Table 1. Network adjustment statistics.

\begin{tabular}{lccc}
\hline \multicolumn{1}{c}{ Statistic } & \multicolumn{3}{c}{ Survey } \\
\cline { 2 - 4 } & March 11-19, 2014 & April 1-4, 2014 & April 20-24, 2014 \\
\hline Number of absolute-gravity stations & 4 & 4 & 4 \\
Degree of polynomial for calibration function & 1 & 1 & 1 \\
Number of relative-gravity differences & 56 & 60 & 59 \\
Number of relative-gravity differences & 7 & 11 & 5 \\
$\quad$ excluded as outliers & 25 & 24 & 25 \\
Number of gravity stations & 1.3 & 1 & 1.3 \\
Standard deviation multiplier & 1.04 & 1.13 & 1.18 \\
Squared root of a posterior variance of unit & & & \\
$\quad$ weight (reference factor) & 36.72 & 49.60 & 51.91 \\
Global model test statistic & 48.60 & 54.57 & 52.19 \\
Critical chi-square value & $1.00032 \pm 0.00164$ & $1.00106 \pm 0.00174$ & $-1.00043 \pm 0.00200$ \\
Relative-gravity meter calibration factor & &
\end{tabular}




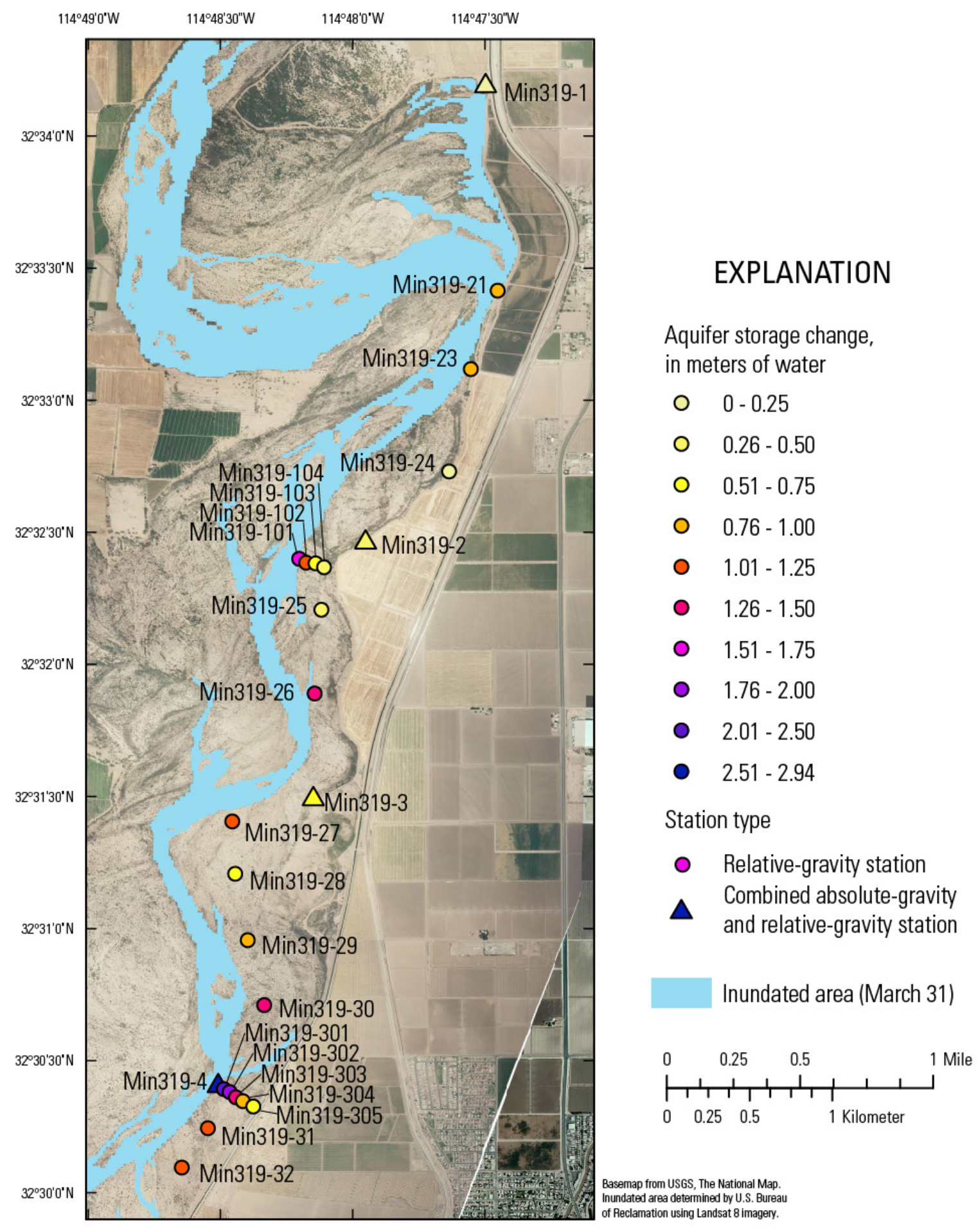

Figure 5. Map showing change in aquifer storage derived from gravity data, from March 11 to April 1 , 2014, in the southern limitrophe reach of the Colorado River, United States-Mexico Border. 


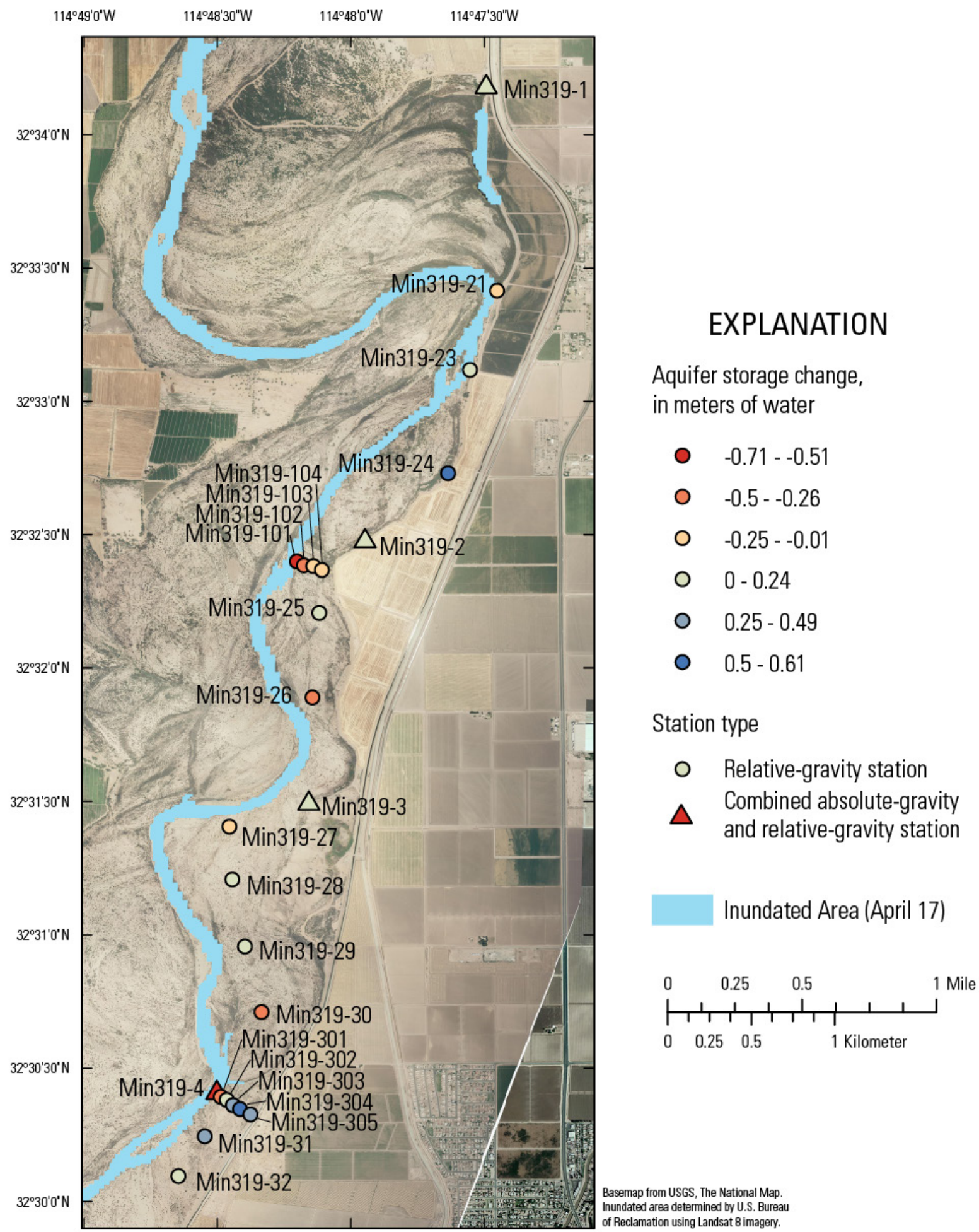

Figure 6. Map showing change in aquifer storage derived from gravity data, from April 1 to 20, 2014, in the southern limitrophe reach of the Colorado River, United States-Mexico Border. 


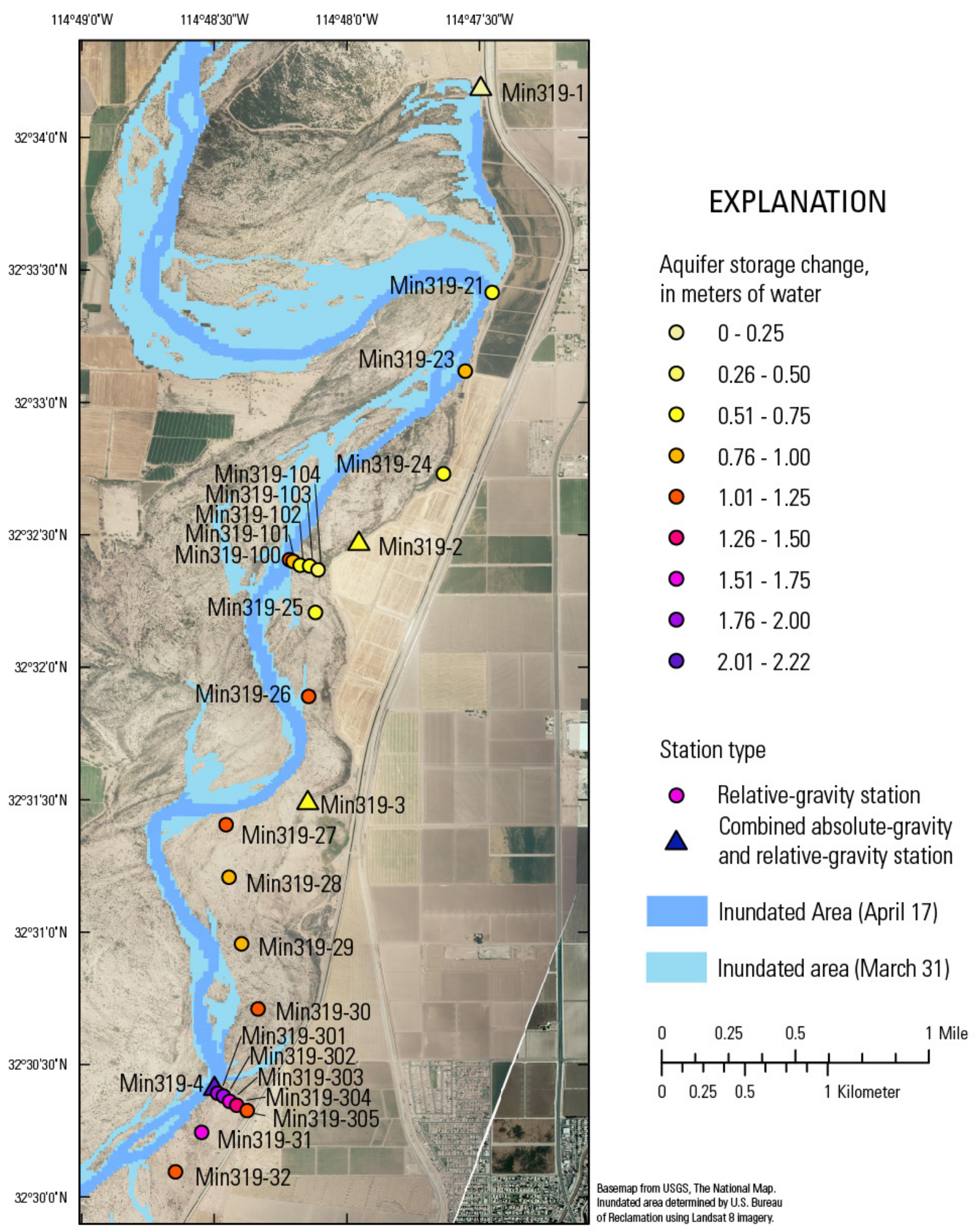

Figure 7. Map showing change in aquifer storage derived from gravity data, from March 11 to April 20, 2014, in the southern limitrophe reach of the Colorado River, United States-Mexico Border. 


\section{Aquifer Storage Change and Specific Yield}

Gravity is measured in units of acceleration (for example, meters per second squared). For a horizontal, unconfined aquifer, the horizontal infinite-slab model (Pool, 2008) can be used to convert acceleration to a change in aquifer storage by the relation

$$
\Delta g=41.9 d
$$

where $\Delta g \quad$ is the measured change in gravity, in units of microgals $\left(1 \mu \mathrm{Gal}=1 \times 10^{-8}\right.$ $\mathrm{m} / \mathrm{s}^{2}$ ), and

$d \quad$ is the one-dimensional aquifer storage change, in meters.

The storage change, $d$, represents freestanding water, and is independent of both depth to water and porosity. In practice, equation 3 is appropriate if the water table is essentially flat, without substantial mounding or depressions, to a distance equal to 10 times the depth to water. These conditions were met at 19 of the 25 gravity stations.

Figures 5, 6, and 7 show the estimated change in aquifer storage at each gravity station between the three survey dates. In general, aquifer storage during the pulse flow shows the greatest increase at stations closest to the river channel, and an overall increase in the southerly direction throughout the limitrophe reach. The pulse flow peaked between the first two surveys, from March 11 to April 1. During this time, the greatest increase in aquifer storage occurred at station Min319-4, where the increase was approximately $2.9 \mathrm{~m}$ (fig. 5). Simultaneously, station Min319-305 (about $250 \mathrm{~m}$ farther away from the channel than Min319-4) experienced an aquifer storage increase of only $0.6 \mathrm{~m}$. During this first period the pattern of gravity change was primarily influenced by the distance between the channel and the gravity station. Between the second and third surveys, from April 1 to April 20, the peak of the pulse flow had passed and the river stage had lowered substantially (fig. 6). Aquifer storage during this period decreased at stations nearest the river but continued to increase away from the river. This pattern reflects a dissipating groundwater mound, as water initially stored underneath and adjacent to the channel was transported laterally through the subsurface away from the channel. Between March 11 and April 20, aquifer storage increased at all stations as a result of infiltrated pulse-flow water (fig. 7). The increase in storage ranged from $0.18 \mathrm{~m}$ at Min319-1, far to the north and away from the channel, to $2.22 \mathrm{~m}$ at Min319-4, adjacent to the channel and one of the farthest south stations.

Specific yield of the aquifer can be determined from co-located gravity and groundwaterlevel data. Specific yield is the one-dimensional change in the volume of water stored in the aquifer (in units of length) per unit of water-level change. The volume of water is measured using the gravity method (Pool and Eychaner, 1995). Specific yield is the slope of the best fit straight line on a plot of aquifer-storage change (as a thickness of water) relative to water-level change. To define this relation, multiple measurements must be made over time, the aquifer storage change must be large enough to be measurable (more than $10 \mathrm{~cm}$, in most cases), and the relationship between gravity and water level must be sufficiently linear. Nonlinear conditions may arise under confined aquifer conditions or where thick unsaturated zones store substantial amounts of infiltrated water that has not yet reached the aquifer (Pool, 2008).

Four gravity stations were co-located with monitoring wells. Gravity stations Min319-23, Min319-25, Min319-28, and Min319 are co-located with U.S. Bureau of Reclamation well BD52 and USGS wells 323212114480701, 323112114482701, and 323042114482001, respectively. The average specific yield at these four locations is $0.32 \pm 0.05$ (fig. 8). 


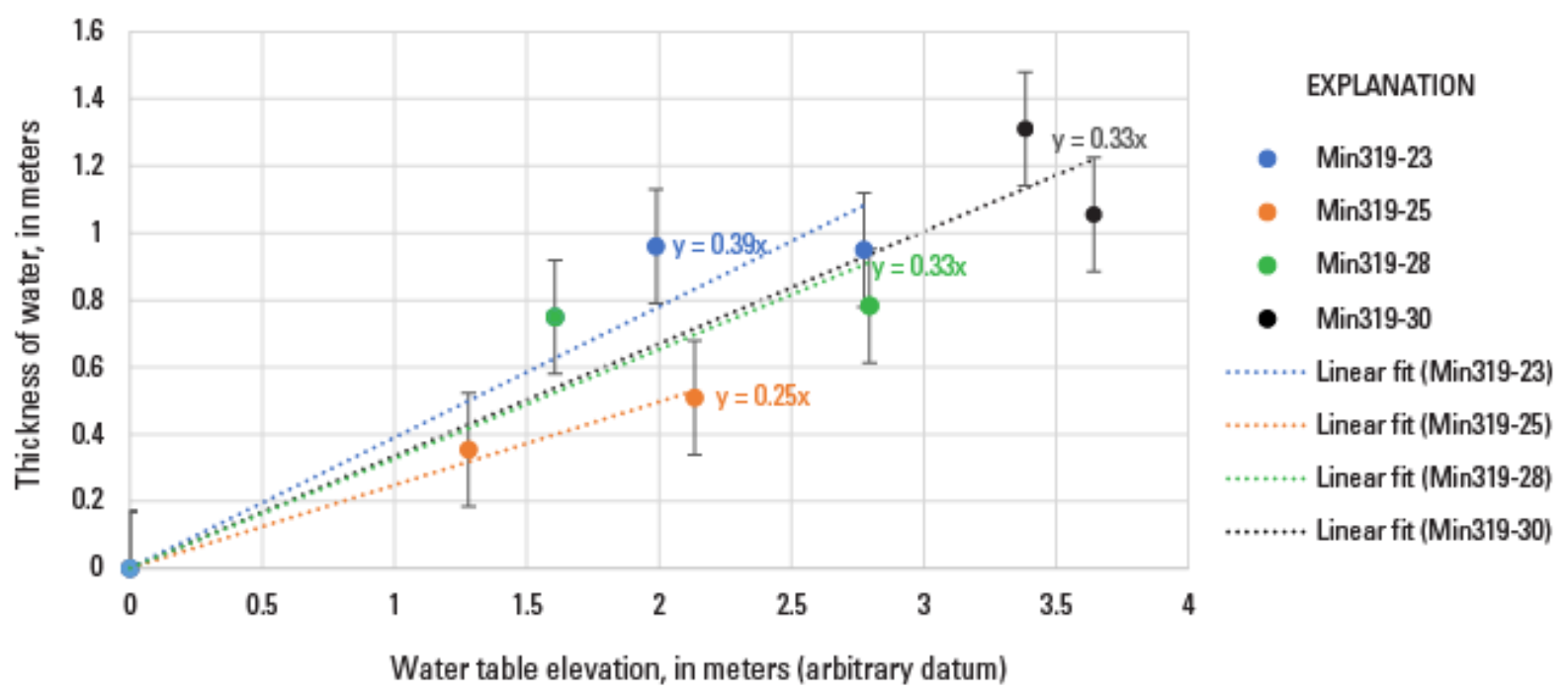

Figure 8. Scatterplot showing specific yield calculation for four locations in the southern limitrophe reach of the Colorado River.

\section{Electromagnetic Induction Data}

For the Minute 319 pulse flow, EMI was used to investigate particle-size distribution (which is related to hydraulic conductivity) in soil and river sediment to a depth of about $15 \mathrm{~m}$ at seven transect locations in the limitrophe reach and five in Mexico (fig. 1). Surveys were carried out by the USGS, UABC, and CICESE during the periods of March 4-7 and 20-22, 2014, prior to the initiation of the pulse flow on March 23, 2014. Measurements were made at 5-m intervals and transect lengths ranged from $55 \mathrm{~m}$ to $200 \mathrm{~m}$. EMI transects were co-located with vegetation transects in order to provide biologists with soil information to help understand and predict seedling growth and establishment.

Electromagnetic induction instruments are used in a wide variety of fields from hydrogeology and agriculture to archeology and contaminant transport (Everett, 2011). Investigations seeking to extract hydrogeologic information in arid environments tend to experience less interference from soil moisture and salinity during dry periods (Callegary and others, 2007a), such as the period immediately prior to the pulse flow. EMI instruments transmit radio-frequency electromagnetic waves (the primary field) into the ground, inducing currents in the subsurface that are proportional to the apparent electrical conductivity $\left(\sigma_{a}\right)$ of a volume of material comprising water, soil, and air (Callegary and others, 2007b, 2012). Electrical conductivity increases with increasing water, clay, and salt content (Revil and others, 2012). The greater the electrical conductivity of the subsurface, the larger the currents induced by the instrument-generated field, and the greater the return (secondary) field sensed by the instrument. Sandy soils and sediments, typical of sites studied in this investigation, tend to have $\sigma_{\mathrm{a}}$ values ranging from near 0 to about 10 millisiemens per meter $(\mathrm{mS} / \mathrm{m})$. Greater values indicate some combination of increased water, salt, and (or) clay content (McNeill, 1980). The lack of precipitation in the study area minimizes temporal variations in water content and accentuates the electrical conductivity contrast between coarse material (sand and gravel have relatively low $\sigma_{a}$ ) and fine material which tends to retain water ( silt and clay have relatively high $\sigma_{a}$ ). EMI 
transects in this study allowed us to map the variations in subsurface materials along this part of the Colorado River.

Variations in $\sigma_{\mathrm{a}}$ were measured using low-induction number, frequency-domain electromagnetic-induction instruments placed on the ground at each measurement location along a transect. Four different EMI instruments from Geonics Ltd. were used, each with different nominal depths of investigation: the EM-38, EM31-MK2, and EM34-3XL (fig. 9). The EM-38 has an intercoil spacing (ICS) of $1 \mathrm{~m}$, an operating frequency of 14,600 Hz, and nominal depths of investigation of $0.75 \mathrm{~m}$ (vertical coplanar coil orientation [VCP]) and $1.5 \mathrm{~m}$ (horizontal coplanar coil orientation [HCP]). The EM31-MK2 has an ICS of $3.66 \mathrm{~m}$ and an operating frequency of $9,800 \mathrm{~Hz}$ with nominal depths of investigation of $3 \mathrm{~m}$ (VCP) and $6 \mathrm{~m}$ (HCP) estimated from one-dimensional approximations (Callegary and others, 2007b, 2012). The EM34-3XL was operated with an ICS of $10 \mathrm{~m}$ and a frequency of $6,400 \mathrm{~Hz}$ with nominal depths of investigation of $7.5 \mathrm{~m}$ (VCP) and $15 \mathrm{~m}$ (HCP). Because EMI measurements actually sample over a volume of the subsurface, the indicated depth is only approximate (Callegary and others, $2007 \mathrm{~b}, 2012$ ). The long axis of each instrument was oriented parallel to the transect and generally perpendicular to the channel thalweg (figs. 9, 10). Additional measurements were made perpendicular to the transect to check for heterogeneity.

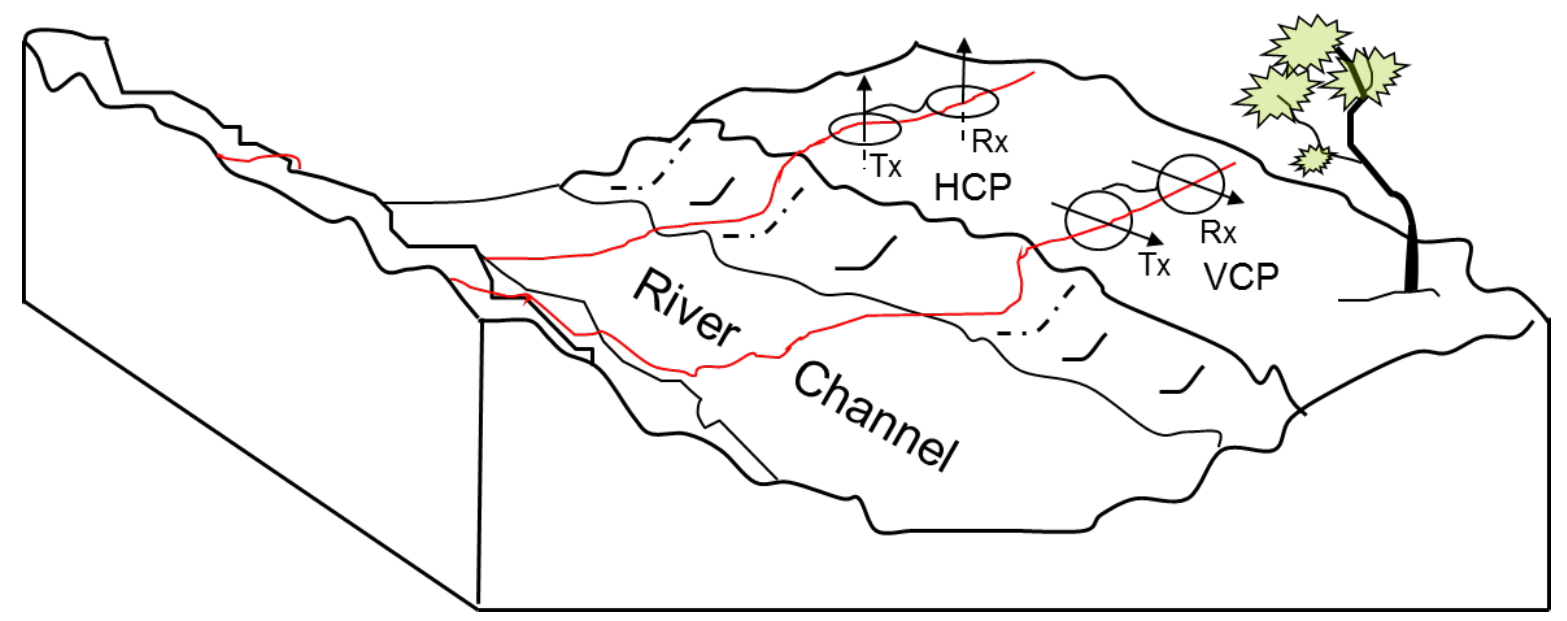

Figure 9. Diagram indicating orientation of transmitter $(\mathrm{Tx})$ and receiver $(\mathrm{Rx})$ coils relative to each other (in vertical coplanar coil orientation [VCP] or horizontal coplanar coil orientation [HCP]), to the soil surface, and to transects (red). 


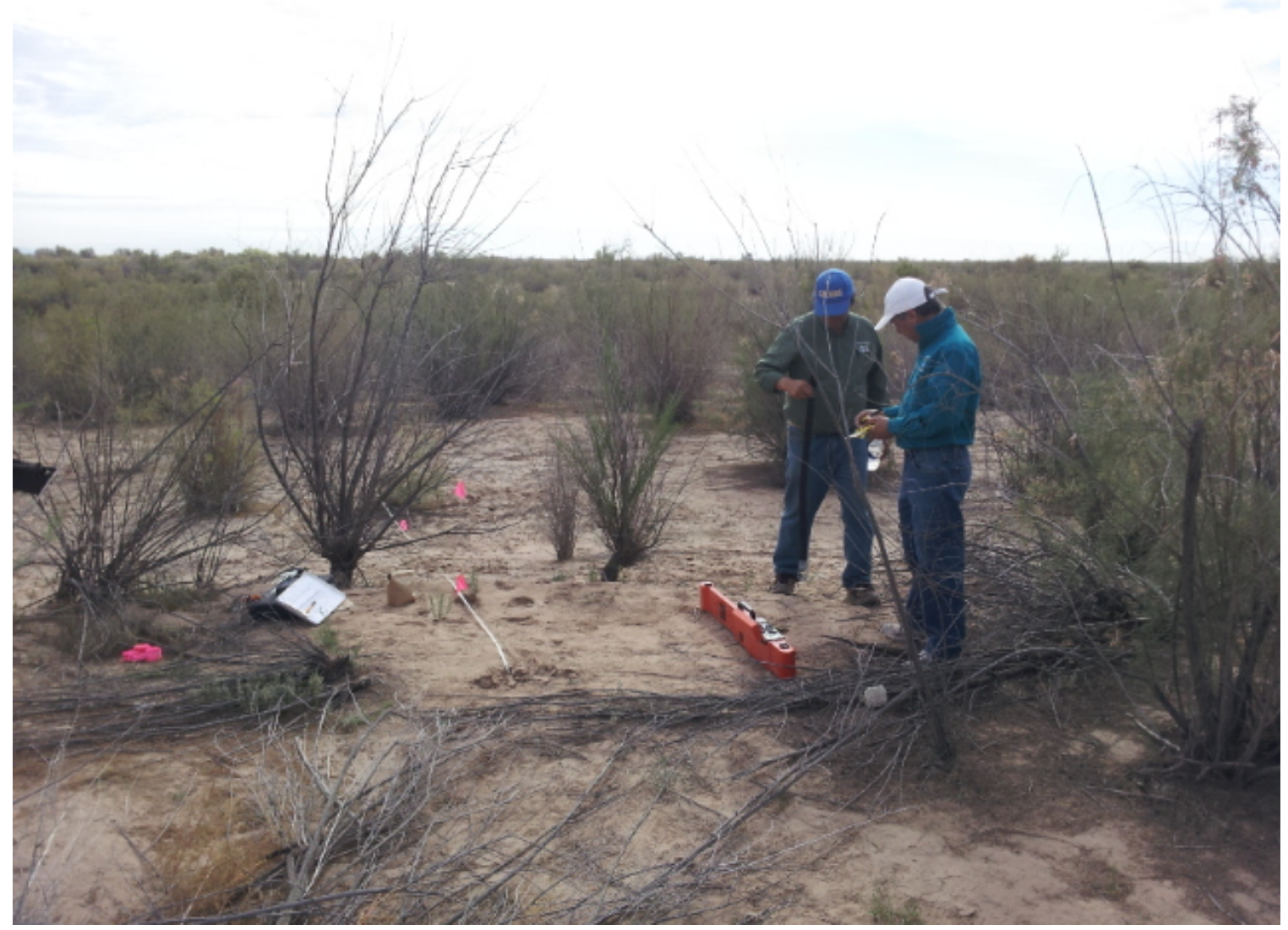

Figure 10. Photograph showing geophysicists preparing to make an electromagnetic induction measurement using an EM-38 instrument. The instrument is in the horizontal coplanar coil orientation (HCP). The coils are built into the instrument and therefore not visible in this photograph. Survey tape and flagging indicate the position of the vegetation transect.

The depth and volume of investigation is controlled by several instrument-related factors including the transmitted frequency and the transmitter-receiver $(\mathrm{Tx}-\mathrm{Rx})$ separation and orientation ( $\mathrm{HCP}$ or $\mathrm{VCP}$ ). Lower frequencies and larger $\mathrm{Tx}-\mathrm{Rx}$ separations allow for greater depths of investigation. The orientation of the Tx and Rx coils changes the depth and shape of the investigation volume (Callegary and others, 2012). The HCP coil orientation gives a greater depth of investigation than the VCP coil orientation. Nominal depths of investigation for each instrument under ideal conditions (referenced above) were given by McNeill (1980), although these are only valid where there are both minimal heterogeneity at the scale of the measurement and where $\sigma_{\mathrm{a}}$ is below about $10 \mathrm{mS} / \mathrm{m}$. As $\sigma_{\mathrm{a}}$ increases, the depth of investigation can decrease by as much as $30-50$ percent (Callegary and others, 2007b). Because only raw, uninverted data are included in this report with values ranging to greater than $60 \mathrm{mS} / \mathrm{m}$, inverse modeling, as suggested by Callegary and others $(2007 \mathrm{~b}, 2012)$, may aid in the interpretation of variations in $\sigma_{a}$ as variations in particle size distribution, moisture content, and salinity.

\section{Transect Data Description and Relation to Site Characteristics}

In general, river corridors, including channel and floodplain locations, tend to be dynamic, moving through time and space, creating heterogeneous landscapes and deposits with 
respect to particle size (Schwendel and others, 2015). Variations in particle size can control water flow and thereby create heterogeneity in water content. We hoped that some of this heterogeneity would be captured by EMI measurements. EMI transects were oriented perpendicular to and across the Colorado River channel with the exception of ST1-3, which was located perpendicular but only on one side of the channel, which is perennial at this location. At upstream in-channel locations, it is less likely that clay and salt are considerable factors contributing to relatively high $\sigma_{\mathrm{a}}$ values, because active stream channels in arid environments commonly have lower proportions of fine sediments than do adjacent overbank deposits (Walling and He, 1998), and this is the case in the part of the Colorado River included in the study area (Mueller and others, 2016). At downstream locations, however, decreasing sediment particle size (that is, increased abundance of clay) (Singer, 2008; Knighton, 1980) and salt (owing to evaporation, higher water tables, and return flows from irrigation) may be factors in higher $\sigma_{\mathrm{a}}$. Values of $\sigma_{\mathrm{a}}$ increased with depth at each transect, with the highest values of $\sigma_{\mathrm{a}}$ usually located under the main river channel (which we define as the widest and lowest nonvegetated part of each transect). Higher values of $\sigma_{\mathrm{a}}$ at depth in the main channel could be the result of higher clay, salt, or water content. Although no subsurface samples were acquired at the transect locations, given the consistency of this depth dependency as opposed to the heterogeneity typical with particle size variability, it is likely that the increasing $\sigma_{\mathrm{a}}$ with depth we observed at most transects was likely due to greater subsurface water content.

When using the EMI data to infer potential spatial correlations between surface and subsurface features, it is important to consider several factors. First, though the data are presented in two dimensions (vertical and horizontal $\sigma_{\mathrm{a}}$ variation along each transect), at any given location the properties of the subsurface may vary in three dimensions. The primary and secondary electromagnetic fields generated during a measurement are also three dimensional. Furthermore, the data as presented here have not been shifted or modified in any way, so negative values are reported. Negative values likely indicate improper calibration or lack of calibration of the instrument prior to the individual survey measurements. Further analysis will be required to assess methods for correcting the data to the range in which they likely would have fallen with proper calibration.

\section{Transect ST1-3}

Transect ST1-3 was $60 \mathrm{~m}$ long and oriented west to east. Elevations ranged from $28.9 \mathrm{~m}$ above sea level at the west end to $26.8 \mathrm{~m}$ above sea level at the east end (fig. 11). The transect did not cross the river channel, which was flowing during the survey, though not because of the pulse flow. Values of $\sigma_{\mathrm{a}}$ ranged from 2.0 to $27.0 \mathrm{mS} / \mathrm{m}$. Values tended to increase from west to east, toward the river. This could be interpreted as an increase in water and (or) clay content. 

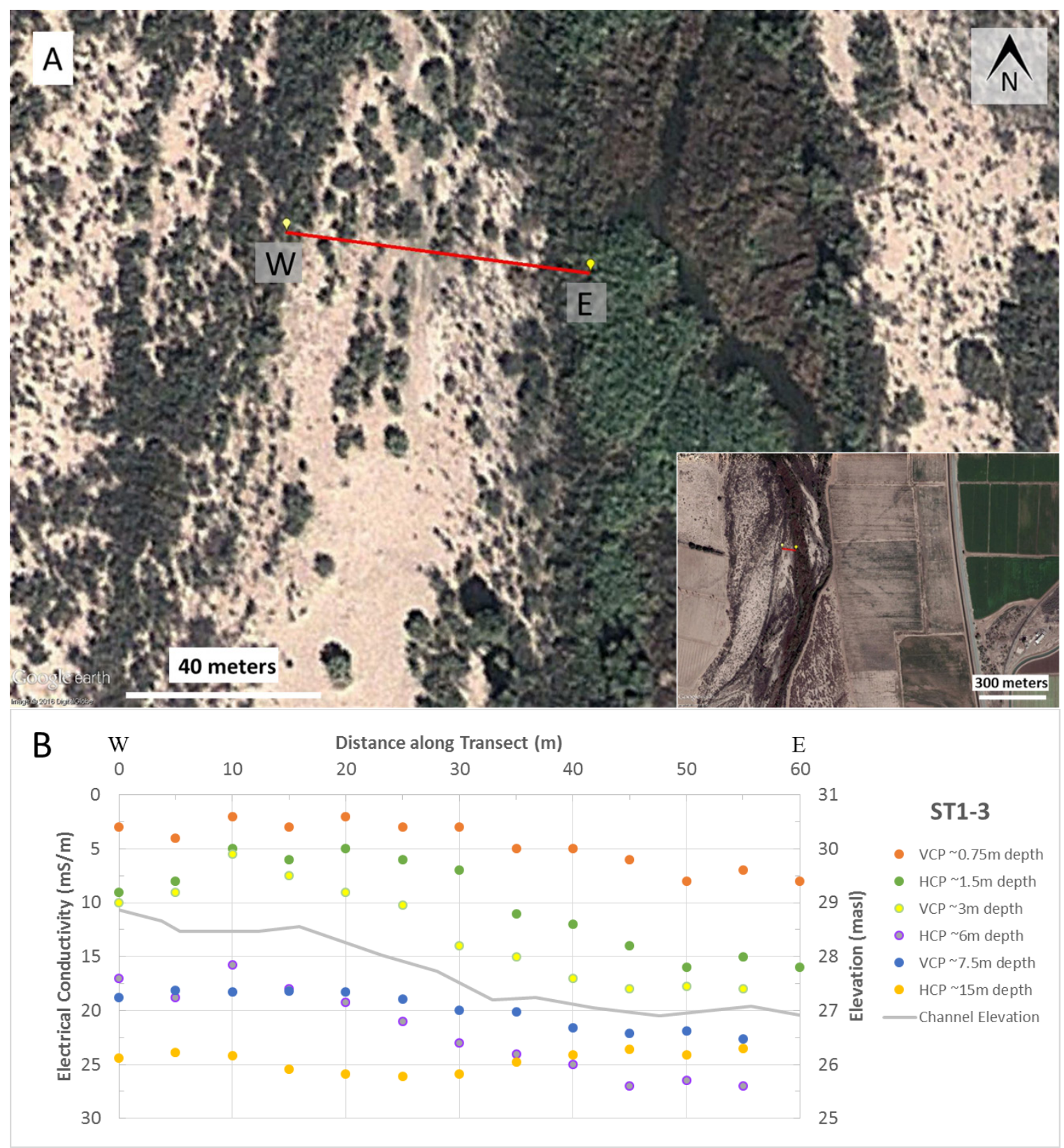

Figure 11. Transect ST1-3 location and data, Colorado River, United States-Mexico Border. A, Aerial image showing location of transect relative to river channel with inset map showing agricultural fields, canals, roads, and the riparian corridor (base imagery date: October 2013, from Google, DigitalGlobe 2016). $B$, Plot of apparent electrical conductivity $\left(\sigma_{a}\right)$ and land elevation versus distance along transect. Measurements were oriented west $(\mathrm{W})$ to east $(\mathrm{E})$. Note that $\sigma_{\mathrm{a}}$ values increase downward. Nominal depths of $\sigma_{a}$ measurements are indicated in the explanation. $\mathrm{mS} / \mathrm{m}$, millisiemens per meter; $\mathrm{m}$, meters; masl, meters above sea level.

\section{Transect ST1-4}

Transect ST1-4 was $120 \mathrm{~m}$ long and oriented west to east. Elevations ranged from $27.5 \mathrm{~m}$ above sea level at the west end, to a low of $24.9 \mathrm{~m}$ above sea level in the channel, to $26.9 \mathrm{~m}$ above sea level at the east end (fig. 12). The main channel was located between 50 and $70 \mathrm{~m}$ 
from the west end of the transect. High-flow channels were located between 12 and $50 \mathrm{~m}$ and between $83 \mathrm{~m}$ and the east end of the transect. Values of $\sigma_{\mathrm{a}}$ ranged from -2.5 to $21.8 \mathrm{mS} / \mathrm{m}$. The highest $\sigma_{\mathrm{a}}$ values in the 6- to 15 -m-depth measurements are generally associated with the location of the main channel, potentially indicating presence of water at depth.

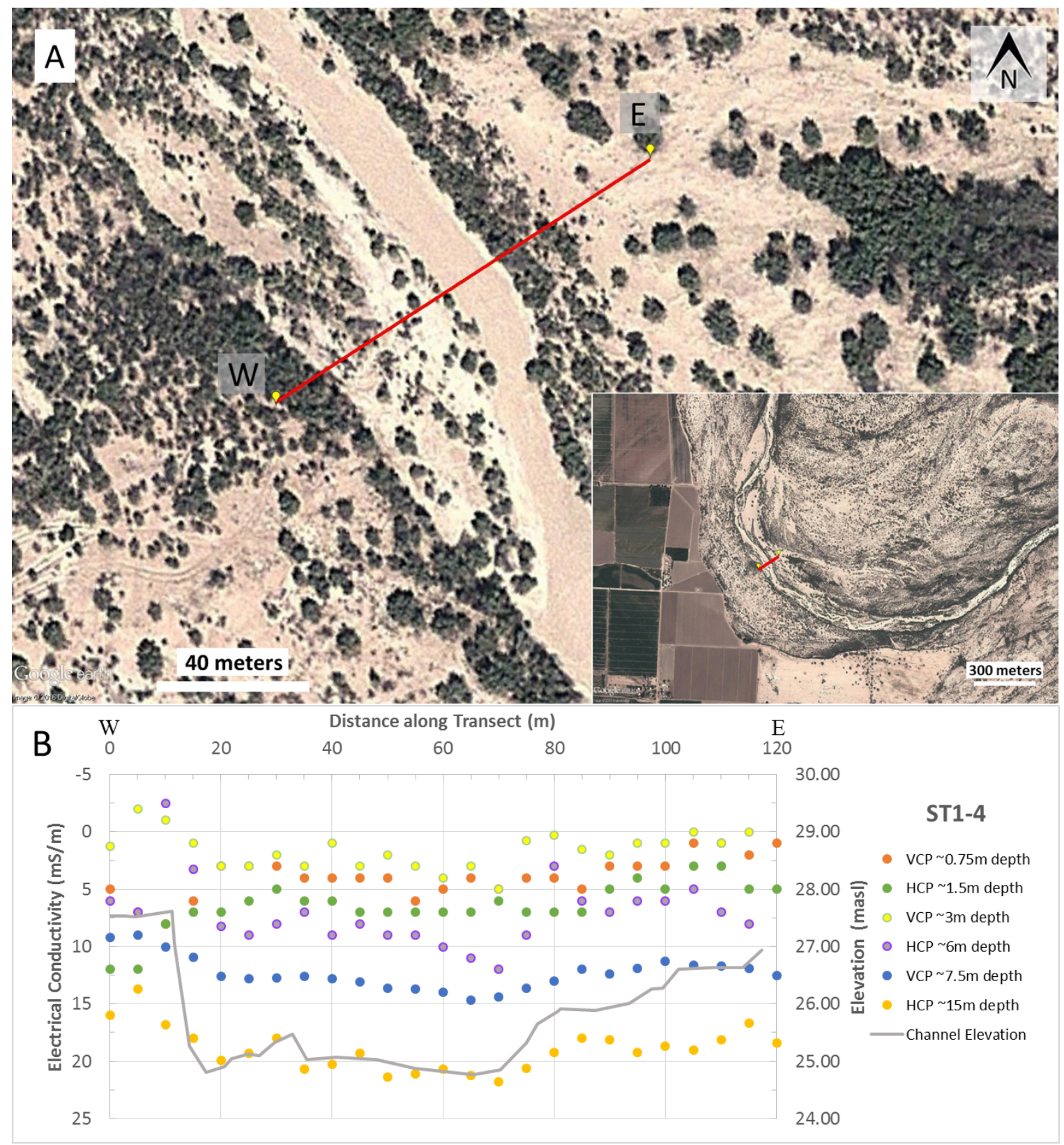

Figure 12. Transect ST1-4 location and data, Colorado River, United States-Mexico Border. A, Aerial image showing location of transect relative to river channel with inset map showing agricultural fields, canals, roads, and the riparian corridor (base imagery date: October 2013, from Google, DigitalGlobe 2016). $B$, Plot of apparent electrical conductivity $\left(\sigma_{a}\right)$ and land elevation versus distance along transect. Measurements were oriented west $(\mathrm{W})$ to east $(\mathrm{E})$. Note that $\sigma_{\mathrm{a}}$ values increase downward. Nominal depths of $\sigma_{a}$ measurements are indicated in the explanation. $\mathrm{mS} / \mathrm{m}$, millisiemens per meter; $\mathrm{m}$, meters; masl, meters above sea level. 


\section{Transect ST2-1}

Transect ST2-1 was $200 \mathrm{~m}$ long and oriented west to east. Elevations ranged from $26.6 \mathrm{~m}$ above sea level at the west end, to a low of $22.7 \mathrm{~m}$ above sea level in the channel, to $27.1 \mathrm{~m}$ above sea level at the east end (fig. 13). There are several small channels between 0 and $25 \mathrm{~m}$ from the west end of the transect. The main channel was located between 53 and $73 \mathrm{~m}$, with another high-flow channel between 81 and $167 \mathrm{~m}$. Values of $\sigma_{\mathrm{a}}$ ranged from -3.5 to $26.7 \mathrm{mS} / \mathrm{m}$. As with ST1-4, the highest values were measured under the main channel. These are not typical of values associated with saturated sediments, but they may indicate increasing clay or water content.

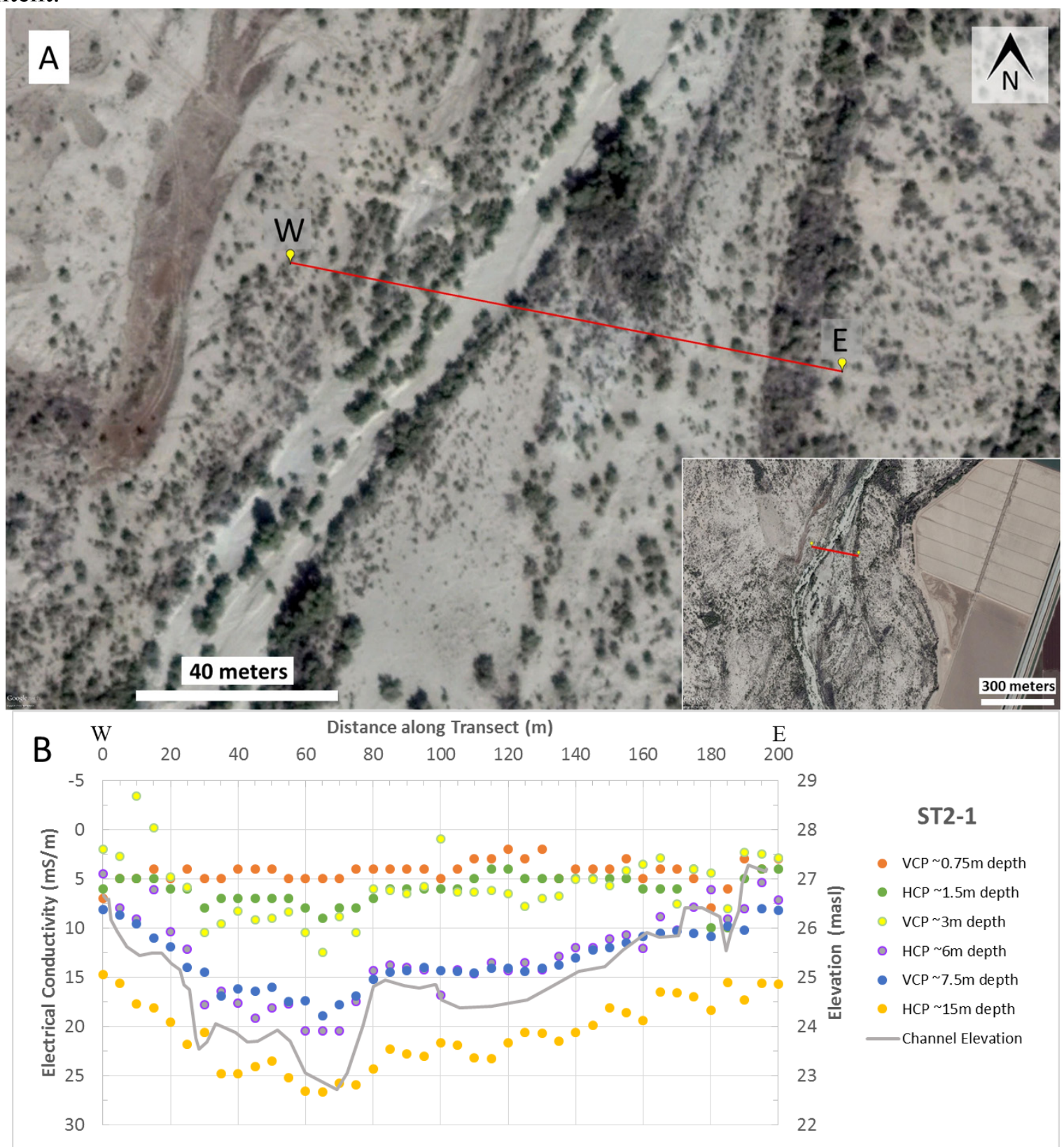

Figure 13. Transect ST2-1 location and data, Colorado River, United States-Mexico Border. A, Aerial image showing location of transect relative to river channel with inset map showing agricultural fields, canals, roads, and the riparian corridor (base imagery date: November 2014, from Google, DigitalGlobe 
2016). $B$, Plot of apparent electrical conductivity $\left(\sigma_{a}\right)$ and land elevation versus distance along transect. Measurements were oriented west $(\mathrm{W})$ to east $(\mathrm{E})$. Note that $\sigma_{\mathrm{a}}$ values increase downward. Nominal depths of $\sigma_{\mathrm{a}}$ measurements are indicated in the explanation. $\mathrm{mS} / \mathrm{m}$, millisiemens per meter; $\mathrm{m}$, meters; masl, meters above sea level.

\section{Transect ST2-2}

Transect ST2-2 was $140 \mathrm{~m}$ long and oriented west to east. Elevations ranged from $26.6 \mathrm{~m}$ above sea level at the west end, to a low of $22.7 \mathrm{~m}$ above sea level in the channel, to $26.0 \mathrm{~m}$ above sea level at the east end (fig. 14). The main channel was located between 20 and $60 \mathrm{~m}$. The transect was heavily vegetated between 90 and $125 \mathrm{~m}$. Values of $\sigma_{\mathrm{a}}$ ranged from 1.0 to 25.4 $\mathrm{mS} / \mathrm{m}$. Locations where measurements diverge could indicate drier or sandier material above and wetter or clayier material below. For example, note the divergence between the VCP $(7.5-\mathrm{m}-$ depth) ICS and the HCP (15-m-depth) ICS between 90 and $125 \mathrm{~m}$ along the transect. 

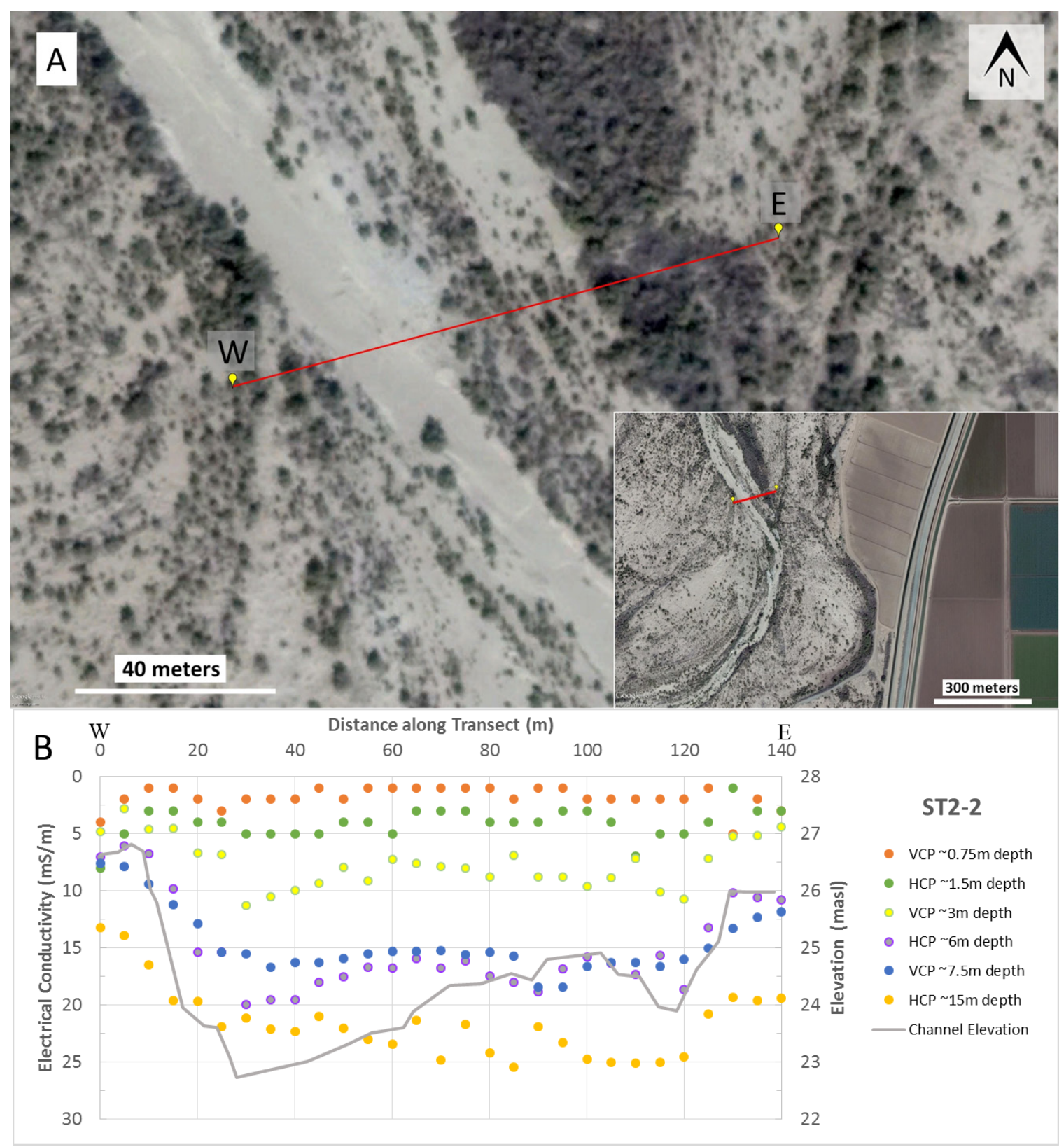

Figure 14. Transect ST2-2 location and data, Colorado River, United States-Mexico Border. A, Aerial image showing location of transect relative to river channel with inset map showing agricultural fields, canals, roads, and the riparian corridor (base imagery date: November 2014, from Google, DigitalGlobe 2016). $B$, Plot of apparent electrical conductivity $\left(\sigma_{a}\right)$ and land elevation versus distance along transect. Measurements were oriented west $(\mathrm{W})$ to east $(\mathrm{E})$. Note that $\sigma_{\mathrm{a}}$ values increase downward. Nominal depths of $\sigma_{a}$ measurements are indicated in the explanation. $\mathrm{mS} / \mathrm{m}$, millisiemens per meter; $\mathrm{m}$, meters; masl, meters above sea level.

\section{Transect ST2-3}

Transect ST2-3 was $120 \mathrm{~m}$ long and oriented west to east. Elevations ranged from $26.2 \mathrm{~m}$ above sea level at the west end, to a low of $22.3 \mathrm{~m}$ above sea level in the channel, to $26.2 \mathrm{~m}$ above sea level at the east end (fig. 15). The main channel was located between the 50 and $75 \mathrm{~m}$. 
Values of $\sigma_{\mathrm{a}}$ ranged from -1.0 to $19 \mathrm{mS} / \mathrm{m}$ (fig. 13). The highest $\sigma_{\mathrm{a}}$ values correspond to the main channel, likely indicating higher moisture content. (The EM-38 ranged erratically from -48 to 70 $\mathrm{mS} / \mathrm{m}$ and the instrument is presumed to have malfunctioned. Thus the $0.75-$ and $1-\mathrm{m}$-depth ICS measurements have been censored from the plot below, but the data are available in the raw data file.)

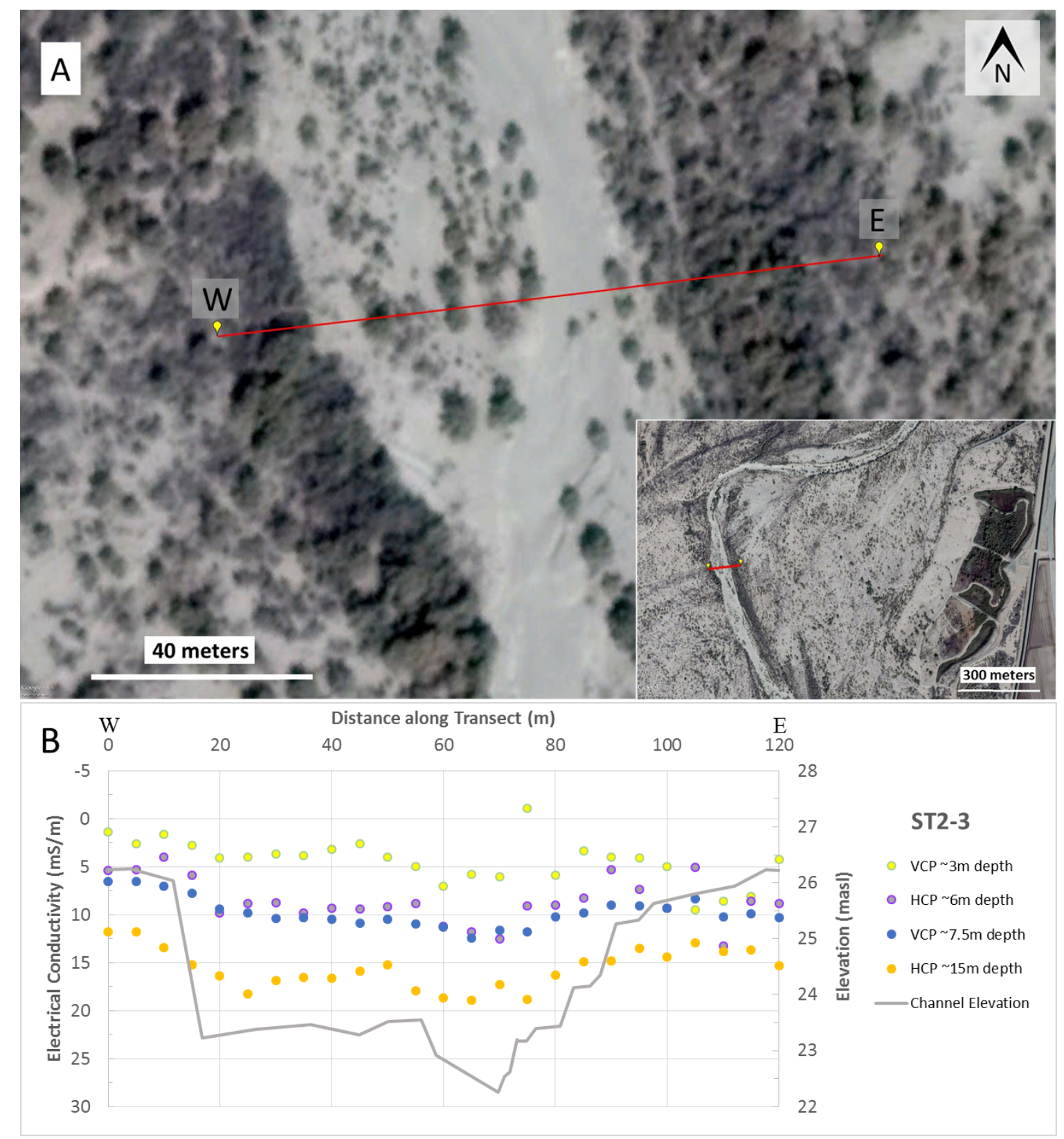

Figure 15. Transect ST2-3 location and data, Colorado River, United States-Mexico Border. A, Aerial image showing location of transect relative to river channel with inset map showing agricultural fields, canals, roads, and the riparian corridor (base imagery date: November 2014, from Google, DigitalGlobe 2016). $B$, Plot of apparent electrical conductivity $\left(\sigma_{a}\right)$ and land elevation versus distance along transect. Measurements were oriented west $(\mathrm{W})$ to east $(\mathrm{E})$. Note that $\sigma_{\mathrm{a}}$ values increase downward. Nominal depths of $\sigma_{a}$ measurements are indicated in the explanation. $\mathrm{mS} / \mathrm{m}$, millisiemens per meter; $\mathrm{m}$, meters; masl, meters above sea level. 


\section{Transect ST2-4}

Transect ST2-4 was $150 \mathrm{~m}$ long and oriented west to east. Elevations ranged from $25.6 \mathrm{~m}$ above sea level at the west end, to a low of $21.9 \mathrm{~m}$ above sea level in the channel, to $25.6 \mathrm{~m}$ above sea level at the east end (fig. 16). The main channel was located between 45 and $65 \mathrm{~m}$. There was also a side channel between 20 and $27 \mathrm{~m}$. Values of $\sigma_{\mathrm{a}}$ ranged from 0.2 to $16.6 \mathrm{mS} / \mathrm{m}$, indicating sandier and (or) drier conditions when compared with the higher values in upstream transects described above (figs. 11-15). This transect is located in the limitrophe reach, in which depth to water increases downriver (Kennedy and others, 2016a). The highest $\sigma_{\mathrm{a}}$ values correspond to the channels. Between 0 and $30 \mathrm{~m}$ and between 110 and $150 \mathrm{~m}$ along the transect, values of $\sigma_{\mathrm{a}}$ tended to increase and become more variable, possibly indicating more clay in those parts of the transect. As mentioned in the introduction to this section, variations of $\sigma_{\mathrm{a}}$ such as these are unsurprising in river sediments, which commonly vary with topographic position and river migration history. 


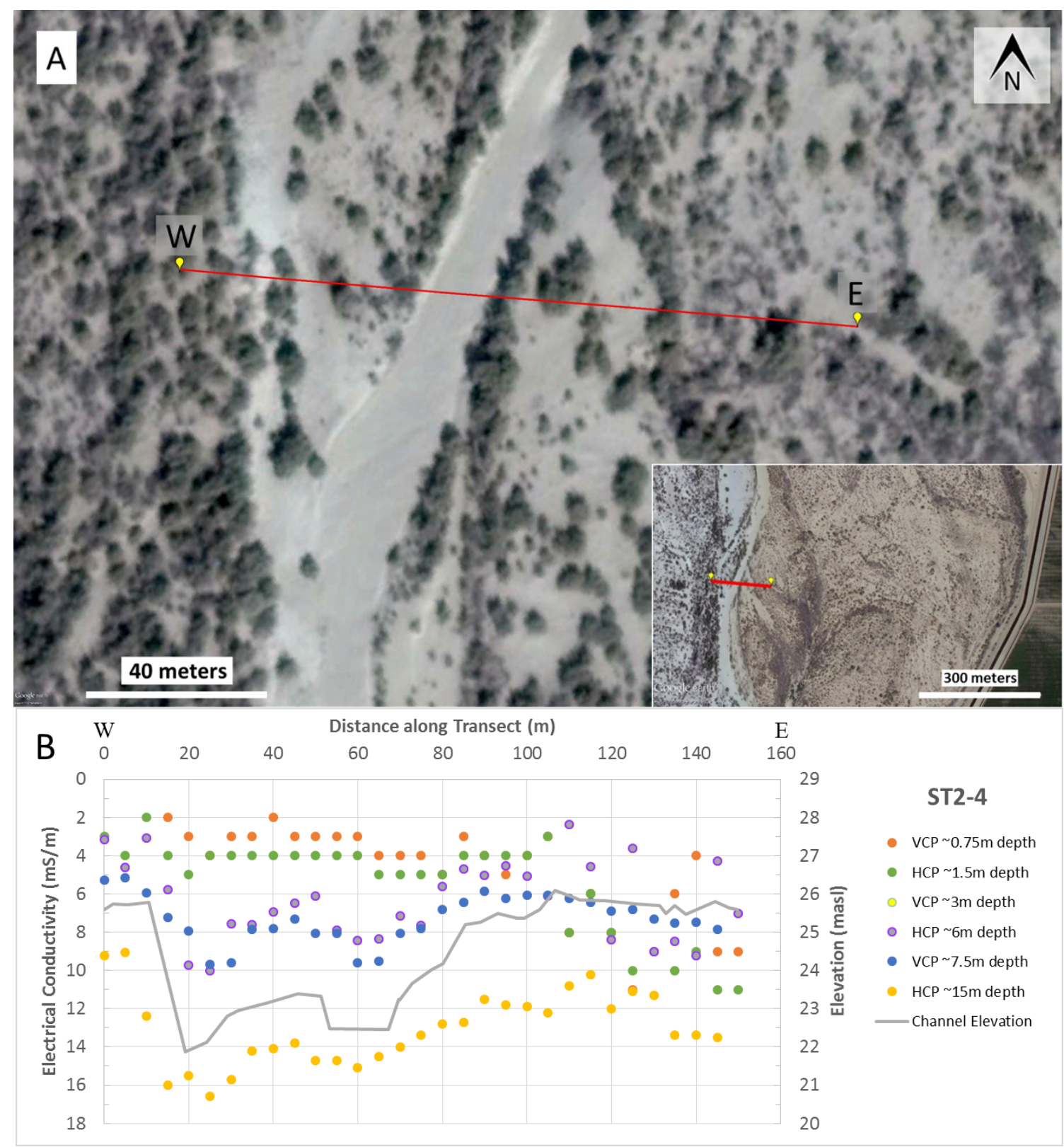

Figure 16. Transect ST2-4 location and data, Colorado River, United States-Mexico Border. A, Aerial image showing location of transect relative to river channel with inset map showing agricultural fields, canals, roads, and the riparian corridor (base imagery date: November 2014, from Google, DigitalGlobe 2016). $B$, Plot of apparent electrical conductivity $\left(\sigma_{a}\right)$ and land elevation versus distance along transect. Measurements were oriented west $(\mathrm{W})$ to east $(\mathrm{E})$. Note that $\sigma_{a}$ values increase downward. Nominal depths of $\sigma_{a}$ measurements are indicated in the explanation. $\mathrm{mS} / \mathrm{m}$, millisiemens per meter; $\mathrm{m}$, meters; masl, meters above sea level.

\section{Transect ST3-1}

Transect ST3-1 was $145 \mathrm{~m}$ long and oriented west to east. Elevations ranged from $25.0 \mathrm{~m}$ above sea level at the west end, to a low of $22.2 \mathrm{~m}$ above sea level in the channel, to $24.7 \mathrm{~m}$ above sea level at the east end (fig. 17). The main channel was located between 15 and $30 \mathrm{~m}$. 
There were secondary channels or inundation areas between 47 and $61 \mathrm{~m}$ and between 73 and $145 \mathrm{~m}$ along the transect. Values of $\sigma_{\mathrm{a}}$ ranged from -1.6 to $10.3 \mathrm{mS} / \mathrm{m}$. This site had the lowest $\sigma_{\mathrm{a}}$ values of all the transects, consistent with the greatest depth to water. The negative values in the EM-38 readings were probably caused by the instrument not being adjusted to zero for this survey. Applying a simple additive shift to the values would likely correct these into a reasonable range. However, relative spatial variations across the survey are likely correct and do not need adjustment. There appears to be some correlation between the location of the stream channels and increases in $\sigma_{\mathrm{a}}$ especially in the deeper measurements.

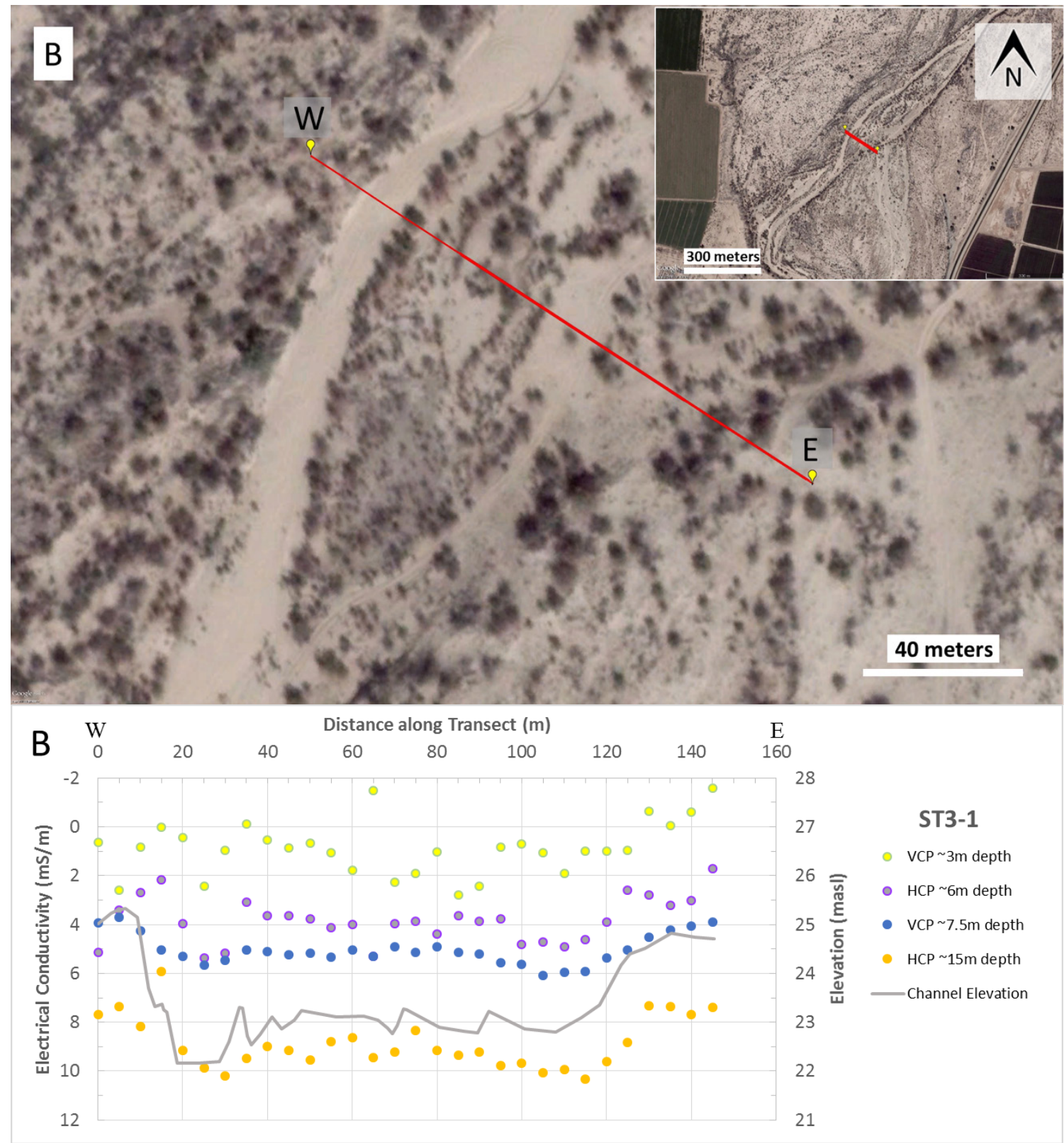

Figure 17. Transect ST3-1 location and data, Colorado River, United States-Mexico Border. A, Aerial image showing location of transect relative to river channel with inset map showing agricultural fields, canals, roads, and the riparian corridor (base imagery date: February 2014, from Google, DigitalGlobe 2016). $B$, Plot of apparent electrical conductivity $\left(\sigma_{a}\right)$ and land elevation versus distance along transect. 
Measurements were oriented west $(\mathrm{W})$ to east $(\mathrm{E})$. Note that $\sigma_{\mathrm{a}}$ values increase downward. Nominal depths of $\sigma_{a}$ measurements are indicated in the explanation. $\mathrm{mS} / \mathrm{m}$, millisiemens per meter; $\mathrm{m}$, meters; masl, meters above sea level.

\section{Transect ST3-2}

Transect ST3-2 was $150 \mathrm{~m}$ long and oriented east to west. Elevations ranged from $28.6 \mathrm{~m}$ above sea level at the east end, to a low of $22.1 \mathrm{~m}$ above sea level in the channel, to $25.2 \mathrm{~m}$ above sea level at the west end (fig. 18). The main channel was located between 10 and $110 \mathrm{~m}$, and there appears to be a high-flow channel between the 110- and 150-m stations. Values of $\sigma_{a}$ ranged from -4 to $38 \mathrm{mS} / \mathrm{m}$. The negative values in the EM-38 readings were probably caused by the instrument not being adjusted to zero for this survey. Applying a simple additive shift to the values would likely correct these into a reasonable range. However, relative spatial variations across the survey are likely correct and do not need adjustment. The lateral variations in $\sigma_{\mathrm{a}}$ do not correlate exactly with the location of the channels. The values of $\sigma_{\mathrm{a}}$ at greater depths at this site represent a substantial increase from those at site ST3-1, and are higher than at any of the other upstream sites as well. These differences could be due to increases in water, clay, or salt content, or some combination thereof. 


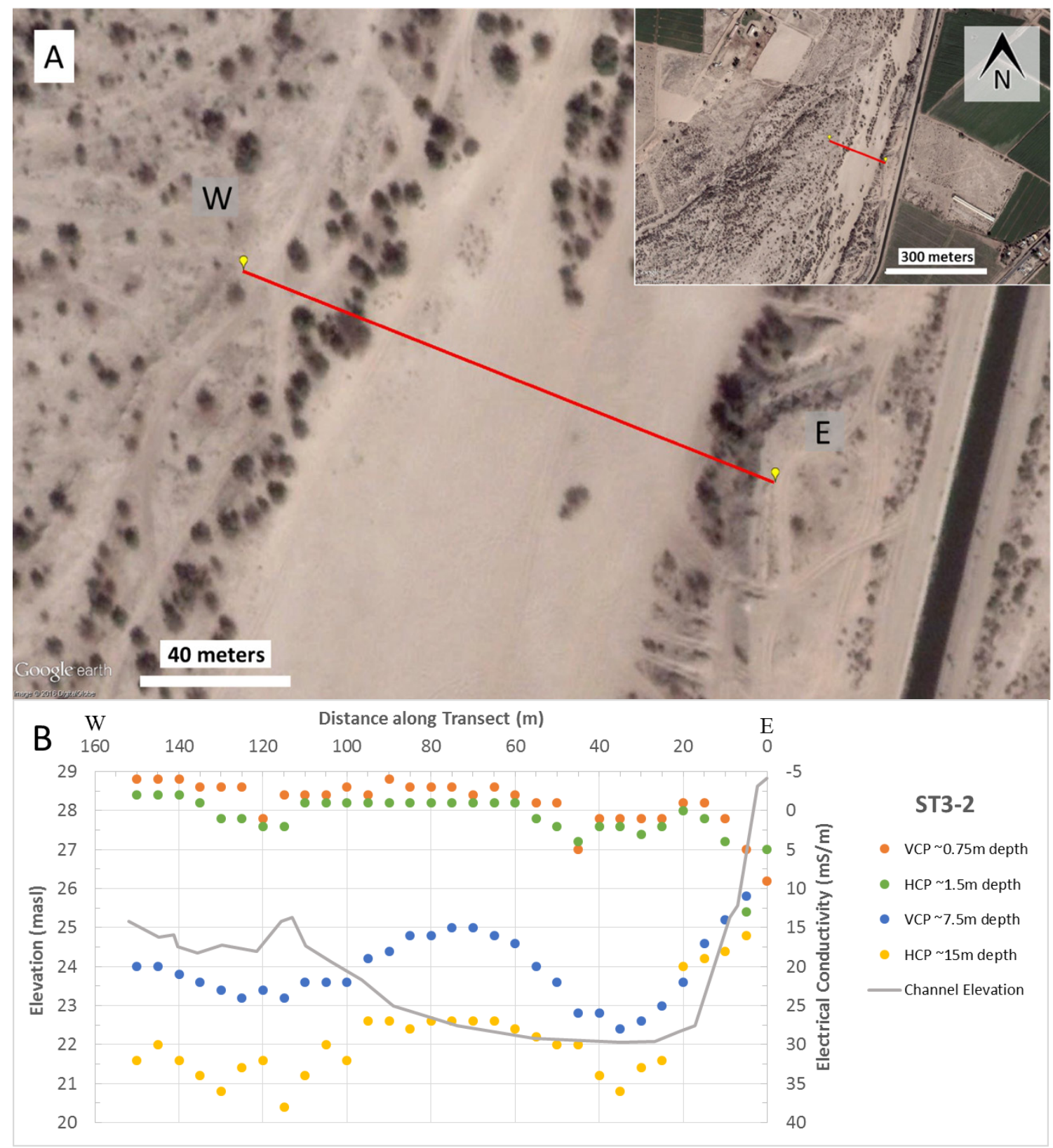

Figure 18. Transect ST3-2 location and data, Colorado River, Mexico. A, Aerial image showing location of transect relative to river channel with inset map showing agricultural fields, canals, roads, and the riparian corridor (base imagery date: February 2014, from Google, DigitalGlobe 2016). B, Plot of apparent electrical conductivity $\left(\sigma_{a}\right)$ and land elevation versus distance along transect. Measurements were oriented east $(E)$ to west (W). Note that $\sigma_{a}$ values increase downward. Nominal depths of $\sigma_{a}$ measurements are indicated in the explanation. $\mathrm{mS} / \mathrm{m}$, millisiemens per meter; $\mathrm{m}$, meters; masl, meters above sea level.

\section{Transect ST3-3}

Transect ST3-3 was $100 \mathrm{~m}$ long and oriented north to south. Elevations ranged from 24.6 $\mathrm{m}$ above sea level at the north end, to a low of $20.4 \mathrm{~m}$ above sea level in the channel, to $24.3 \mathrm{~m}$ above sea level at the south end (fig. 19). From north to south, a wide secondary channel was located between the 17- and 45-m mark. The main (deepest) channel was located between 65 and 
$75 \mathrm{~m}$ from the north end of the transect. Values of $\sigma_{\mathrm{a}}$ ranged from -8.0 to $28.0 \mathrm{mS} / \mathrm{m}$. The negative values in the EM-38 readings were probably caused by the instrument not being adjusted to zero for this survey. Applying a simple additive shift to the values would correct these into a reasonable range. As at other sites, the deeper parts of the channel generally correspond with some of the highest $\sigma_{\mathrm{a}}$ values, likely owing to increased moisture, clay, or salt content.

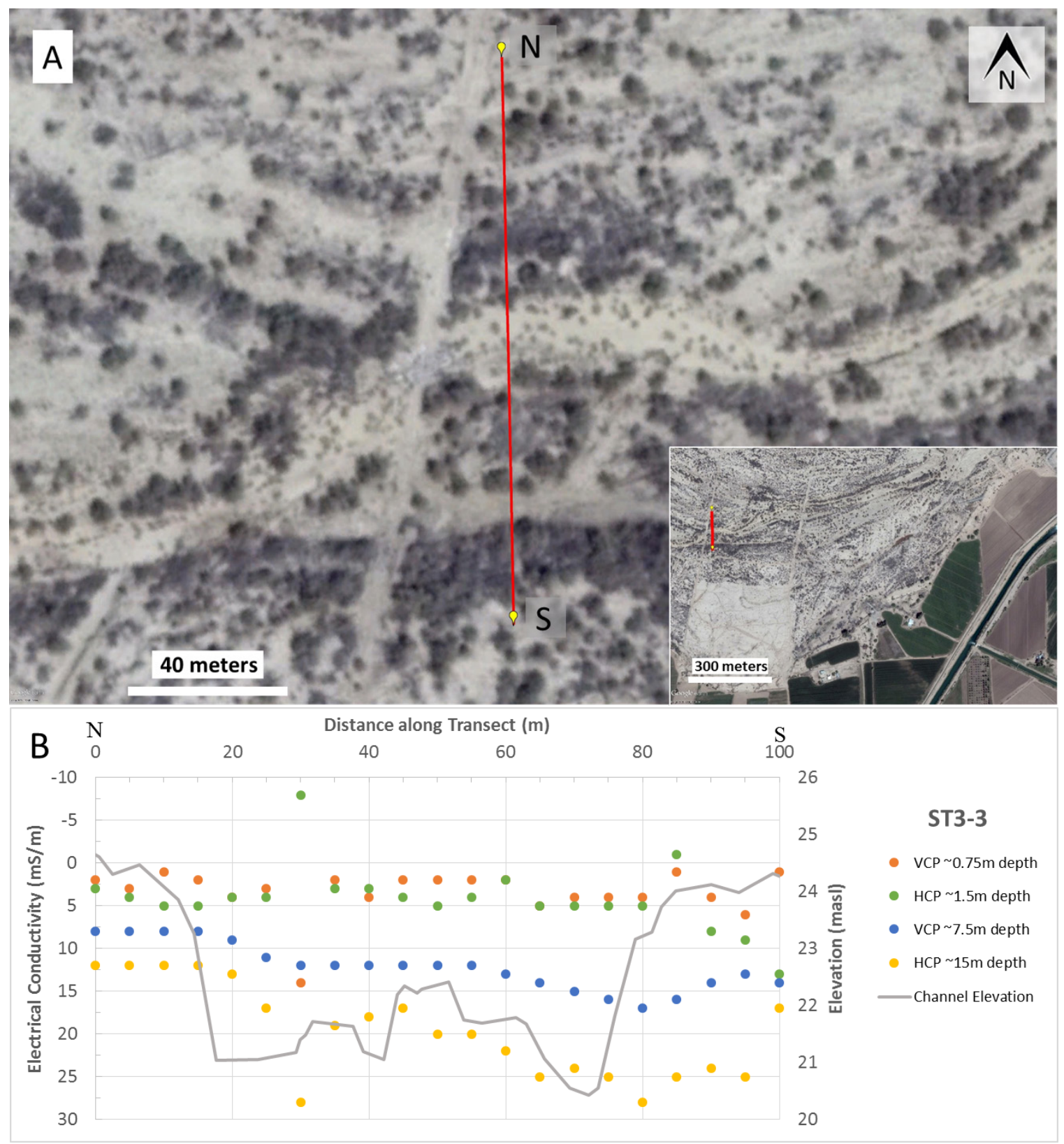

Figure 19. Transect ST3-3 location and data, Colorado River, Mexico. A, Aerial image showing location of transect relative to river channel with inset map showing agricultural fields, canals, roads, and the riparian corridor (base imagery date: February 2014, from Google, DigitalGlobe 2016). B, Plot of apparent electrical conductivity $\left(\sigma_{a}\right)$ and land elevation versus distance along transect. Measurements were oriented from north (N) to south (S). Note that $\sigma_{a}$ values increase downward. Nominal depths of $\sigma_{a}$ measurements are indicated in the explanation. $\mathrm{mS} / \mathrm{m}$, millisiemens per meter; $\mathrm{m}$, meters; masl, meters above sea level. 


\section{Transect ST3-4}

Transect ST3-4 was $105 \mathrm{~m}$ long and oriented east to west. Elevations ranged from $23.1 \mathrm{~m}$ above sea level at the east end, to a low of $19.8 \mathrm{~m}$ above sea level in the channel, to $23.3 \mathrm{~m}$ above sea level at the west end (fig. 20). The main channel was located between 54 and $71 \mathrm{~m}$. A broad low-slope riverbank as well as high-flow channels were located between 18 and $50 \mathrm{~m}$. Values of $\sigma_{\mathrm{a}}$ ranged from 2.0 to $23.0 \mathrm{mS} / \mathrm{m}$. The lowest $\sigma_{\mathrm{a}}$ values in the deeper measurements appear to correspond with the main channel, potentially indicating higher water content.

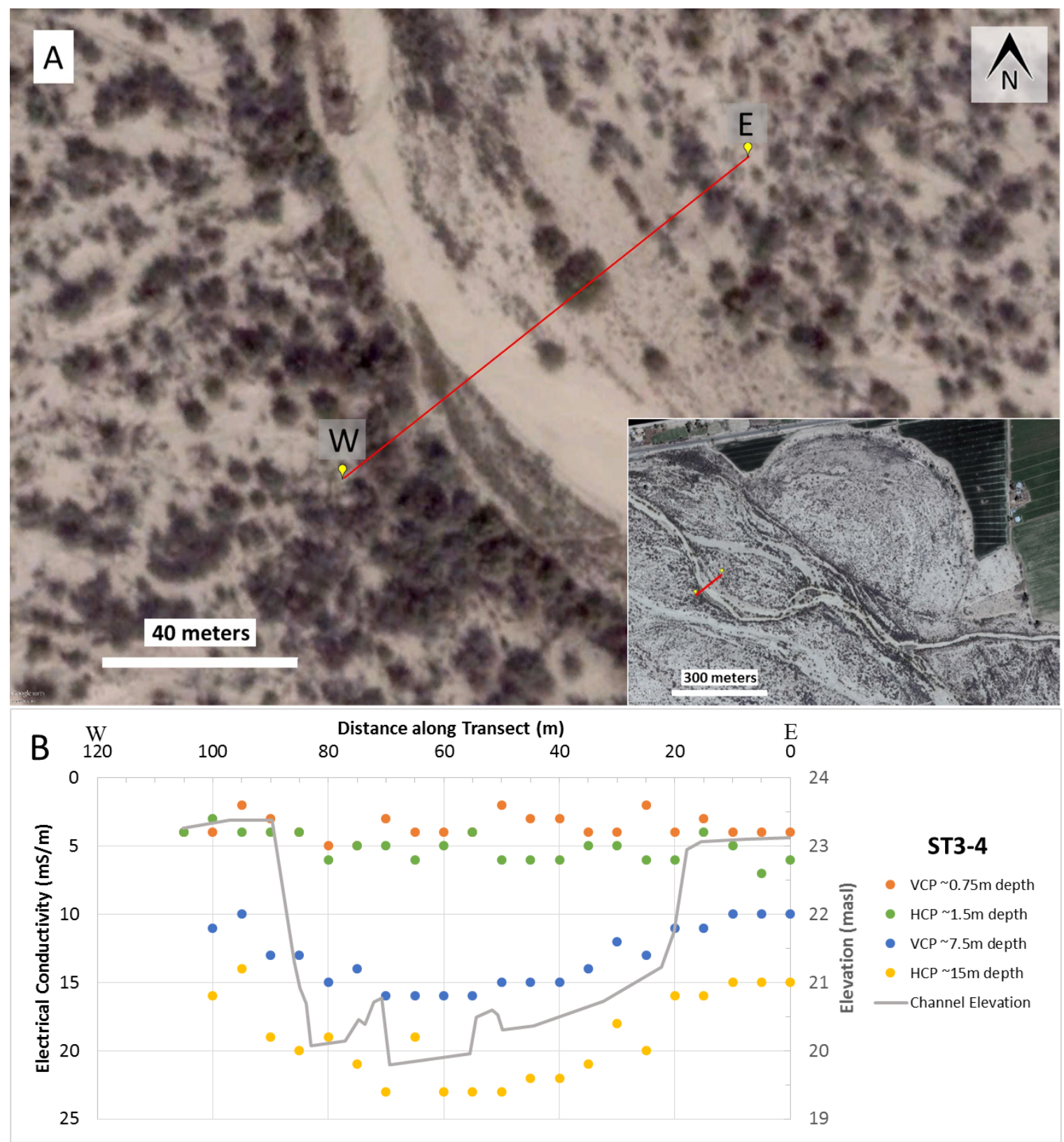

Figure 20. Transect ST3-4 location and data, Colorado River, Mexico. A, Aerial image showing location of transect relative to river channel with inset map showing agricultural fields, canals, roads, and the riparian corridor (base imagery date: February 2014, from Google, DigitalGlobe 2016). B, Plot of apparent electrical conductivity $\left(\sigma_{\mathrm{a}}\right)$ and land elevation versus distance along transect. Measurements were oriented east $(E)$ 
to west $(\mathrm{W})$. Note that $\sigma_{\mathrm{a}}$ values increase downward. Nominal depths of $\sigma_{\mathrm{a}}$ measurements are indicated in the explanation. $\mathrm{mS} / \mathrm{m}$, millisiemens per meter; m, meters; masl, meters above sea level.

\section{Transect ST3-5}

Transect ST3-5 was $250 \mathrm{~m}$ long and oriented east to west. Elevations ranged from $22.7 \mathrm{~m}$ above sea level at the west end, to a low of $17.2 \mathrm{~m}$ above sea level in the channel, to $19.9 \mathrm{~m}$ above sea level at the east end (fig. 21). There were side channels located between 18 and $60 \mathrm{~m}$. The main channel was located between 125 and $185 \mathrm{~m}$. Values of $\sigma_{\mathrm{a}}$ ranged from -5.0 to 30 $\mathrm{mS} / \mathrm{m}$. The shallow measurements have values of $\sigma_{\mathrm{a}}$ that were unusually constant relative to the other sites investigated. This could indicate a problem with the instrument, so caution should be used in interpreting these values. Variations of $\sigma_{\mathrm{a}}$ do not correlate closely with channel locations.

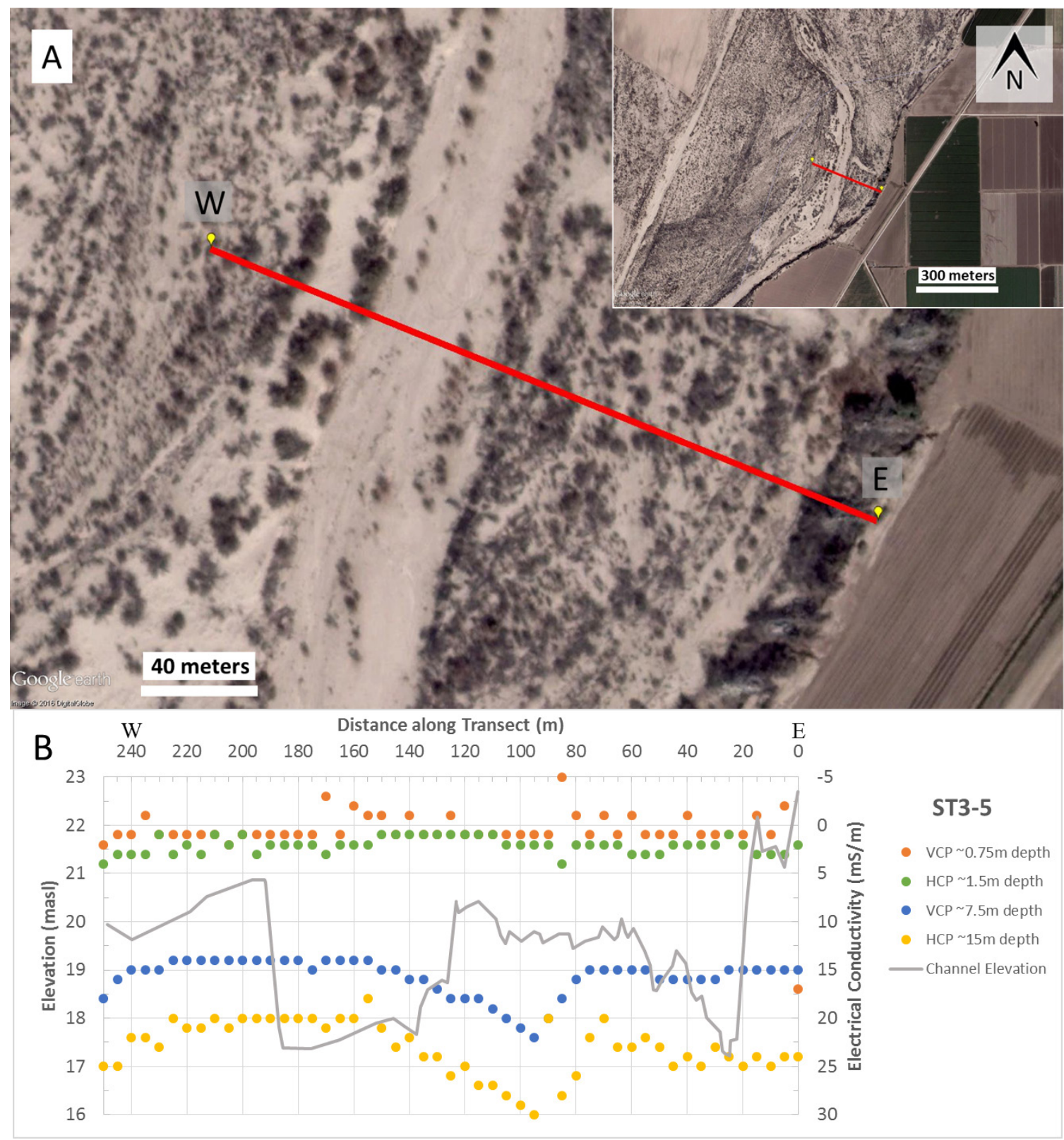


Figure 21. Transect ST3-5 location and data, Colorado River, Mexico. A, Aerial image showing location of transect relative to river channel with inset map showing agricultural fields, canals, roads, and the riparian corridor (base imagery date: February 2014, from Google, DigitalGlobe 2016). B, Plot of apparent electrical conductivity $\left(\sigma_{a}\right)$ and land elevation versus distance along transect. Measurements were oriented east $(E)$ to west (W). Note that $\sigma_{a}$ values increase downward. Nominal depths of $\sigma_{a}$ measurements are indicated in the explanation. $\mathrm{mS} / \mathrm{m}$, millisiemens per meter; $\mathrm{m}$, meters; masl, meters above sea level.

\section{Transect ST3-6}

Transect ST3-6 was $120 \mathrm{~m}$ long and oriented west to east. Elevations ranged from $19.4 \mathrm{~m}$ above sea level at the west end, to a low of $14.6 \mathrm{~m}$ above sea level in the channel, to $17.8 \mathrm{~m}$ above sea level at the east end (fig. 22). The channel was braided at this location with side channels between 15 and $30 \mathrm{~m}$ and between 33 and $48 \mathrm{~m}$. The deepest part of the channel was between 55 and $108 \mathrm{~m}$. Values of $\sigma_{\mathrm{a}}$ ranged from 2.0 to $65 \mathrm{mS} / \mathrm{m}$ (fig. 20); these were the highest values of all the transects. The high $\sigma_{\mathrm{a}}$ values are recorded in the deepest measurements and are likely indicative of some combination of greater water, salt, or clay content than found at other locations. Clay content tends to increase downstream in river systems, but the water table and salt concentrations may also be higher at locations downstream of the Southerly International Boundary owing to return flows from agricultural drains and canals. 


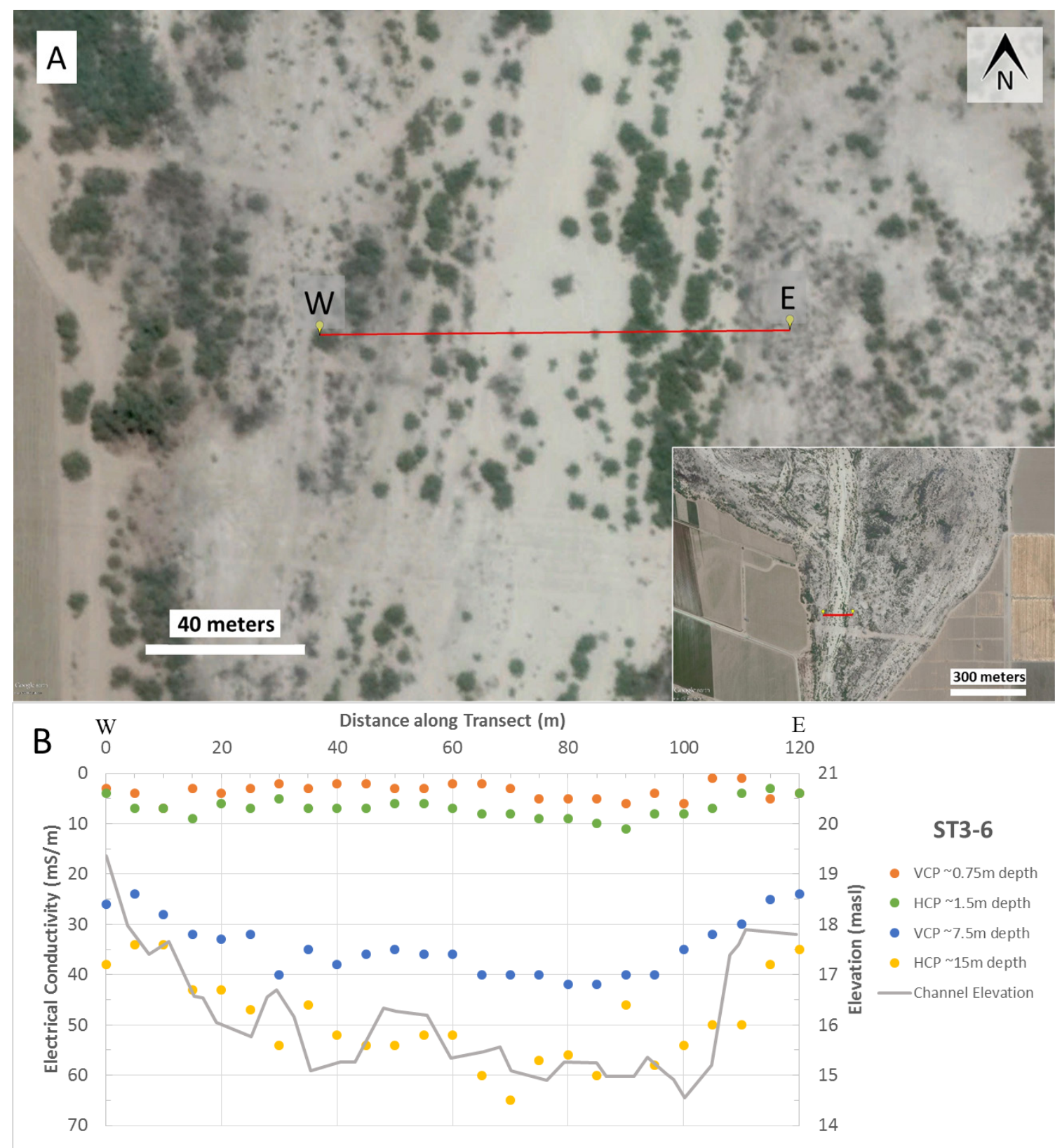

Figure 22. Transect ST3-6 location and data, Colorado River, Mexico. A, Aerial image showing location of transect relative to river channel with inset map showing agricultural fields, canals, roads, and the riparian corridor (base imagery date: July 2014, from Google, DigitalGlobe 2016). B, Plot of apparent electrical conductivity $\left(\sigma_{a}\right)$ and land elevation versus distance along transect. Measurements are oriented west (W) to east $(E)$. Note that $\sigma_{a}$ values increase downward. Nominal depths of $\sigma_{a}$ measurements are indicated in the explanation. $\mathrm{mS} / \mathrm{m}$, millisiemens per meter; $\mathrm{m}$, meters; masl, meters above sea level.

\section{Direct-Current Resistivity Data}

Direct-current resistivity measurements were made to observe changes in the water table during the pulse flow. Resistivity is a measure of the opposition to flow of an electrical current through a material, typically is measured in ohm-meters (ohm-m). Resistivity values for common 
near-surface earth materials vary by orders of magnitude, typically from 1,000 ohm-m or more for dry carbonates and crystalline rocks, to $1 \mathrm{ohm}-\mathrm{m}$ or less for clays and alluvium saturated with high-salinity water (Palacky, 1987). The resistivity of a formation is dependent on saturation, porosity, fracturing, conductivity of fluids within the rock, and mineral composition (Zohdy and others, 1974). Saturated sediment has a lower resistivity value than unsaturated and dry sediment. Where subsurface materials are homogeneous, spatial variations in resistivity can infer variations in water content. For this investigation several resistivity transects were repeatedly surveyed as the surface flow infiltrated. The variations in resistivity among the repeated surveys are due entirely to variations in subsurface water content because that was the only changing variable during the relatively short period during which measurements were made.

For the resistivity method, an electrical current $(I)$, is transmitted into the ground at two electrodes (forming a dipole) and the resulting potential differences $(V)$ are measured between other dipoles at the surface (fig. 23; Sharma, 1997). Layers within the Earth with variable resistivity will distort the expected potentials measured at the surface. Lateral resolution and depth of investigation are determined by the distance between electrodes or dipole length; the farther the electrodes are spaced, the greater the depth of investigation. The spatial configuration of dipoles can be arranged in different geometries to optimize the detection of subsurface electrical structure. The electrode geometry used for this investigation is known as a dipoledipole array where the potential electrodes lie outside of the current electrodes, with each dipole having a constant separation (Hallof, 1992). In the typical dipole-dipole array, the distance between the current and potential dipole pairs $(n a)$ is larger than the spacing of the dipoles $(a)$. During a dipole-dipole survey data are collected as apparent resistivity values. The equation used for calculating apparent resistivity using dipole-dipole configuration is

$$
\rho_{a}=(\pi) n a(n+1)(n+2) V / I
$$

where $\rho_{a} \quad$ is the calculated apparent resistivity,

$n \quad$ is the integer number of dipole spacings between the current and potential electrodes,

$a \quad$ is the length of the dipole,

$V \quad$ is the voltage, and

I is the current (Sharma, 1997). 


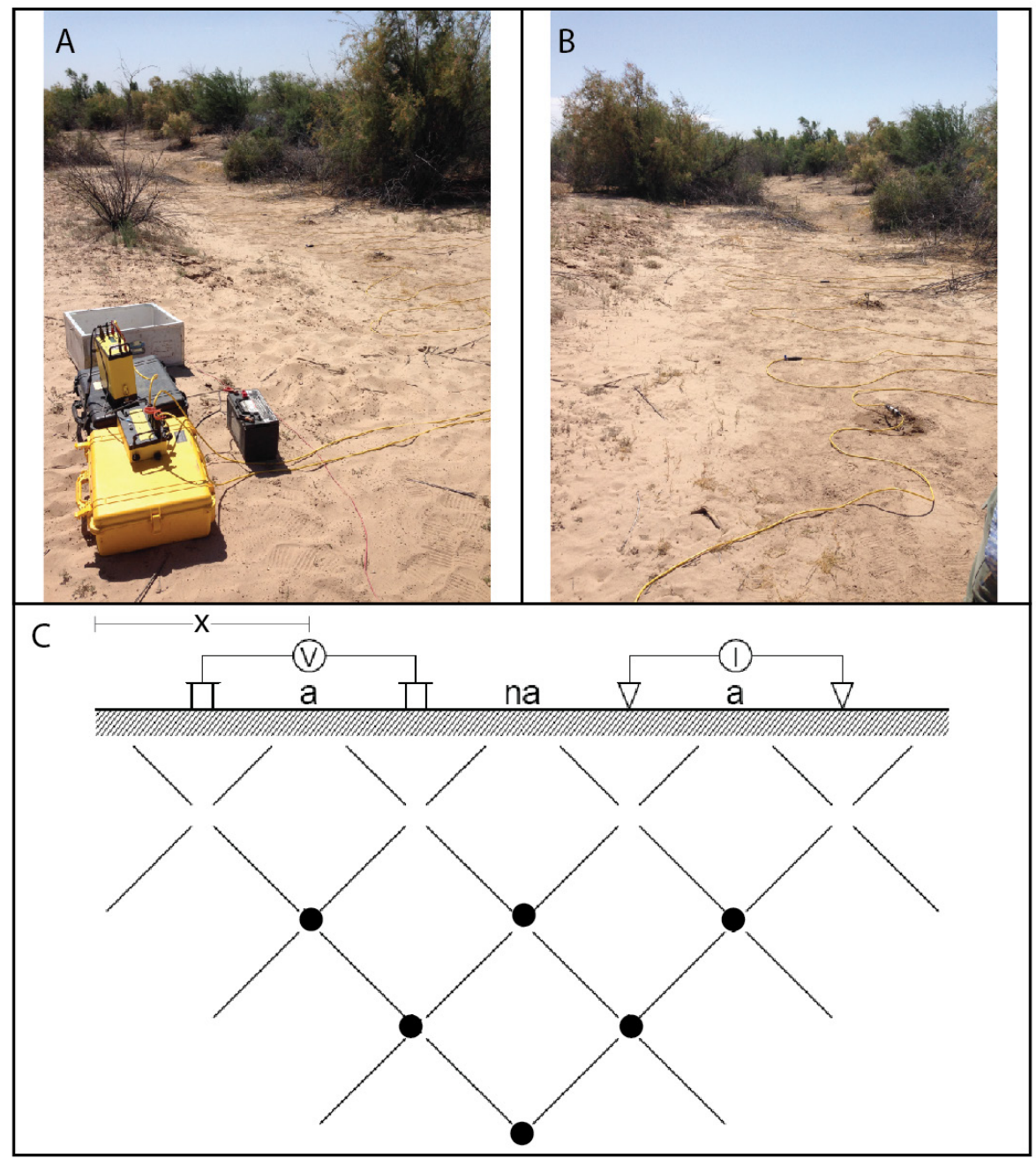

Figure 23. Dipole-dipole resistivity field setup and survey. $A$ and $B$, Photographs showing the dipoledipole resistivity field setup. $C$, diagram of dipole-dipole resistivity survey. $x$, distance from an arbitrary beginning point; V, measured potential dipole; I, transmitting dipole; a, dipole spacing; na, distance between receiving and transmitting dipoles.

Apparent resistivity can be considered the bulk average resistivity for a subsurface that is heterogeneous and anisotropic, traits which include the spatial distribution and type of rocks, minerals, and solutes included in the sample volume. Although bulk resistivity estimates are useful, they do not offer a detailed picture of different layers in the subsurface. Inverse modeling methods are commonly used to estimate the true subsurface resistivity distribution based on electrode geometries, current magnitude, and measured potential (Sharma, 1997). For this study, inversion routines began with models composed of layered rectangular blocks within individual resistivity values. A forward model determined the calculated system response over the model area. Over several model iterations, the inversion process altered the model until the difference between the calculated and measured apparent resistivity values was minimized. The final model is a non-unique estimate of the probable distribution of resistivity values in the subsurface.

For this study, resistivity data were collected using a Sting R1 DC earth resistivity meter (Advanced Geosciences, Inc.). Electrodes were wetted using a $\mathrm{NaCl}$ solution (1 pound of $\mathrm{NaCl}$ per 5 gallons of water) to improve electrical contact with extremely dry sediments. Electrical 
current levels during the survey were typically on the order of 500 milliamps (mA) but were as great as $750 \mathrm{~mA}$. Initial apparent resistivity values were entered into an inverse modeling program that considered resistivity changes in the vertical and horizontal directions along a survey line. EarthImager 2D resistivity modeling software (Advanced Geosciences, Inc.) was used for all dipole-dipole resistivity inverse modeling. Field data loaded into EarthImager were processed through a series of modeling and data reduction steps to produce model inversion profiles with the best fit results to the data.

Repeat time-lapse DC resistivity surveys were used to monitor groundwater infiltration and the subsequent rise of the water table at two sites approximately 32 and $50 \mathrm{~km}$ downstream from Morelos Dam (figs. 24 and 25, respectively). Surveys were conducted by scientists from the USGS, CICESE, and UABC. The sites were located where access to the river channel was possible and in locations near stream-gaging stations. The upstream site, Transect 10 (fig. 24), was $84 \mathrm{~m}$ long, consisted of 28 electrodes running parallel to the Colorado River channel, and was measured nine times on March 23, 25-28, and April 1, 2014. The pulse flow arrived at this site on March 26. The data collection period included two surveys prior to the arrival of the pulse flow (March 23 and 25), four surveys during the first 3 days of flow at the site (March 26-28), and one survey on April 1,9 days after the release began and 7 days after flow began at the site. Water-level measurements were made near Transect 10 at well 323212114480701 before and after the pulse flow to guide the initial subsurface model used in the inversion process. At the downstream site, Transects 20 and 21 (fig. 25) were established, each $135 \mathrm{~m}$ long and consisting of 28 electrodes. Transect 21 was parallel to the river channel and Transect 20 was perpendicular. Water arrived at the site on March 28, 2014, and surveys were conducted on March 14, 26, 29, and April 6 on the perpendicular transect and March 26, 28, and 29 on the parallel transect. 


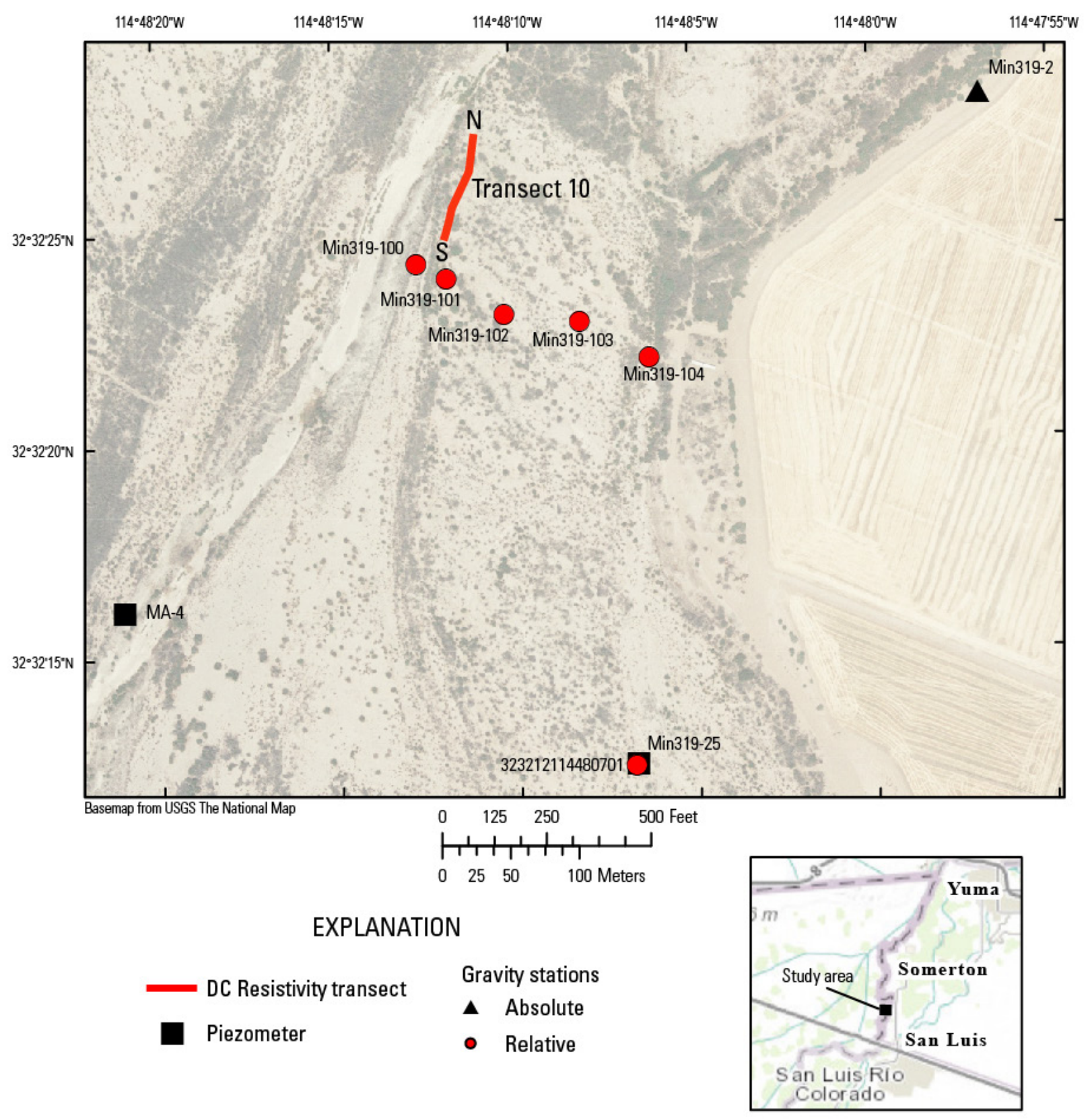

Figure 24. Map showing the location of the U.S. Geological Survey direct-current (DC) resistivity Transect 10 and nearby piezometers and gravity stations, Colorado River, Arizona. 


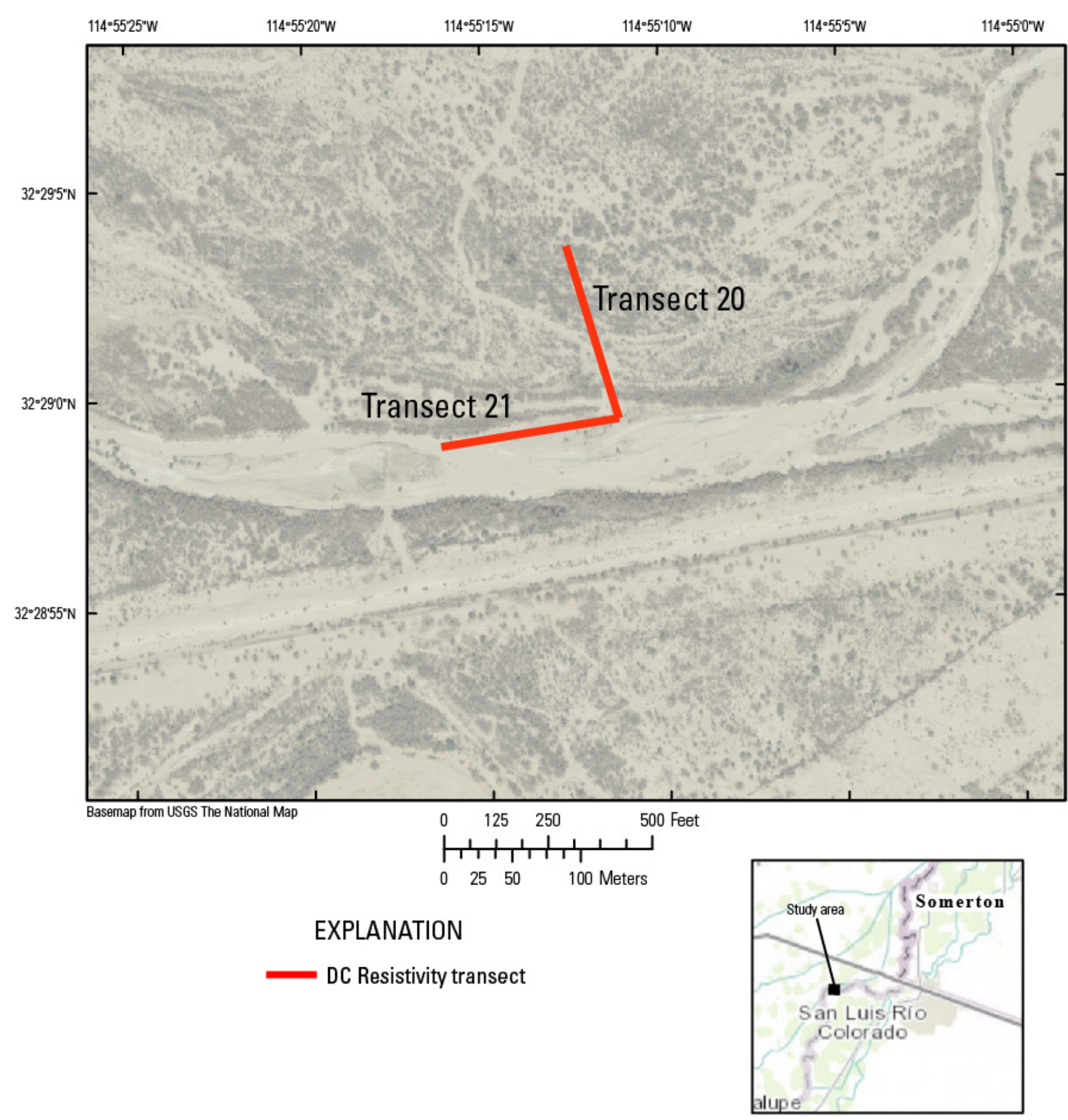

Figure 25. Map showing the location of the UABC and CICESE direct-current (DC) resistivity Transect 20 and Transect 21, Colorado River, Mexico.

\section{Transect 10}

Surveys at Transect 10 can be approximately grouped into three periods: pre-pulse flow (March 23 and 25, 2014), early pulse-flow peak (March 26-27, 2014), and late pulse-flow peak (March 28 and April 1). Figure 23 shows daily inverted model sections for Transect 10 from March 23, March 25-28, and April 1, 2014; two surveys were carried out on March 27, 2014. Inverted model sections from the surveys conducted on March 23 and 25, 2014, represent conditions before infiltration from the pulse flow (fig. 26). On March 23, 2014, modeled data 
extend to a depth of about $17 \mathrm{~m}$ and most of the inverted section was resistive (red-green) with resistivity values ranging from more than $100 \mathrm{ohm}-\mathrm{m}$ to $10,000 \mathrm{ohm}-\mathrm{m}$ (model depth is determined from the resolution of the data during the inversion process). A small section from about electrodes 48 to 72 at a depth of $9 \mathrm{~m}$ to $17 \mathrm{~m}$ contained some conductive material (blue). Prior to the pulse flow the water level at well 323212114480701 (about $200 \mathrm{~m}$ from the river channel) was about $7 \mathrm{~m}$ below land surface. A second inverted resistivity section surveyed on the morning of March 25, 2014, also represents conditions prior to the pulse flow. Most of the inverted section was resistive (red-green). Similar to the survey on March 23, 2014, an area between electrodes 51 and 72 contained some conductive material.

Two inverted model sections that show large resistivity changes below 9-m depth represent the period during the early part of the pulse-flow peak (March 26-27). Pulse flow water arrived at Transect 10 during the evening of March 25, 2014, and a resistivity survey at this transect was carried out on the morning of March 26, 2014, representing the beginning of infiltration from the pulse flow. Material deeper than $9 \mathrm{~m}$ that was previously represented as resistive (red) became less resistive (green; fig. 26). Although these inverse models treat the data as two dimensional, at any given location the properties of the subsurface may vary in three dimensions. As pulse-flow water infiltrated the subsurface, inverted resistivity models representing subsurface conditions continued to change. Areas that were more resistive (red) became less resistive (green and blue; fig. 26). An inverted resistivity section from the survey conducted on the morning of March 27, 2014, showed the continued change from more resistive material to less resistive and conductive material. This inverted resistivity section showed less resistive (green) and more conductive (blue) material at depths below $9 \mathrm{~m}$ (fig. 26). These areas were resistive (red) during the pre-pulse-flow surveys conducted on March 23, 2014.

Resistivity sections from the afternoon of March 27, 2014, also showed the trend of changing from resistive material to more conductive material. Previously resistive (red) material from the March 23, 2014, inverted resistivity section became less resistive (green) and more conductive (blue) material at depths below $9 \mathrm{~m}$ (fig. 26). There was slightly more conductive material (blue) in the March 27, 2014, afternoon inverted section when compared to the March 27, 2014, morning inverted section.

The late part of the pulse-flow peak (March 28 and April 1, 2014) is represented by resistivity changes to $6.5-\mathrm{m}$ depth. An inverted resistivity section from the survey conducted on the morning of March 28, 2014, showed increasingly conductive material (blue) at depths below $9 \mathrm{~m}$ (fig. 26). Depths of about $6.5 \mathrm{~m}$ also showed changes based on the inverted section from March 28, 2014. Previously resistive (red) material became less resistive (yellow-green) and more conductive (blue) material. The final inverted resistivity section was surveyed 4 days later on April 1, 2014. Resistive (red) material at depths below $5 \mathrm{~m}$ became less resistive (green and blue; fig. 26). A water level measured at well 323212114480701 on April 1, 2014, was about 6 $\mathrm{m}$ below land surface.

\section{Transect 20}

Resistivity values at transect 20 ranged from 1 to 10,000 ohm-m (fig. 27). From the surface to about $10 \mathrm{~m}$, values greater than $100 \mathrm{ohm}-\mathrm{m}$ indicated the presence of dry sand. Resistivity variations at the ends of Transect 20 may be due to the lack of data, a common result with this method. Below 10-m depth, values lower than $300 \mathrm{ohm}-\mathrm{m}$ were observed, which can be related to the water content in the aquifer. The pre-pulse-flow period at Transect 20 was captured in the resistivity survey from March 14, 2014, and the early part of the pulse-flow peak was 
captured in the survey on March 26, 2014. The later part of the pulse-flow peak was captured in surveys on March 29 and April 6, 2014. The day after the arrival of water (March 29, 2014), a mild response is apparent only in the first $10 \mathrm{~m}$ of horizontal distance along transect 20 from the south, although values less than $10 \mathrm{ohm}-\mathrm{m}$ are accentuated in the area that is considered the aquifer. On April 6, 2014, resistivity decreased owing to the presence of water. From these values it is deduced the aquifer level rose $5 \mathrm{~m}$ above the pre-pulse level. This influence of the moisture front can be seen in Transect 20 at a distance of 65 to $70 \mathrm{~m}$. Lower resistivity, less than $10 \mathrm{ohm}-\mathrm{m}$, was likely related to the presence of clay, which is typical in this depositional environment. On April 23, 2014, the water level at well C-11-25 03ACC1 was about $9 \mathrm{~m}$ below land surface.

\section{Transect 21}

Resistivity values at transect 21 ranged from 1 to $10,000 \mathrm{ohm}-\mathrm{m}$ (fig. 28). This transect was located within the riverbed at the edge of the channel so it shows the high rate of infiltration caused by a predominantly sandy texture. On March 28, 2014, the day that water arrived at the transect, the subsurface responded rapidly. Resistivity decreased to $100 \mathrm{ohm}-\mathrm{m}$ in the part of transect that was underwater (approximately $75 \mathrm{~m}$ to $135 \mathrm{~m}$ along transect, and upper $4 \mathrm{~m}$ ). The next day (March 29, 2014), with the river channel totally inundated, resistivity values varied from 10 to $100 \mathrm{ohm}-\mathrm{m}$, related to wet sand with wet clay zones and saturation of the entire subsurface. 
Transect 10

N

March 23, 2014

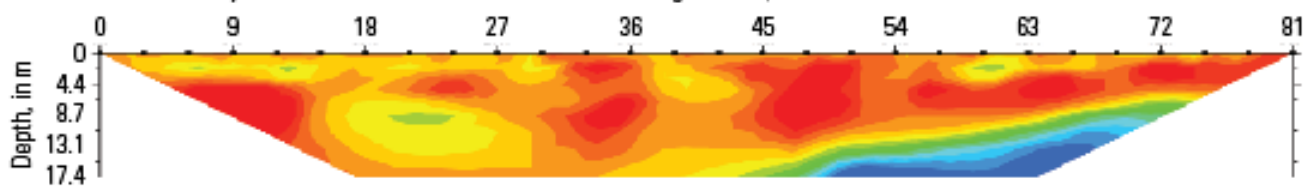

March 25, 2014

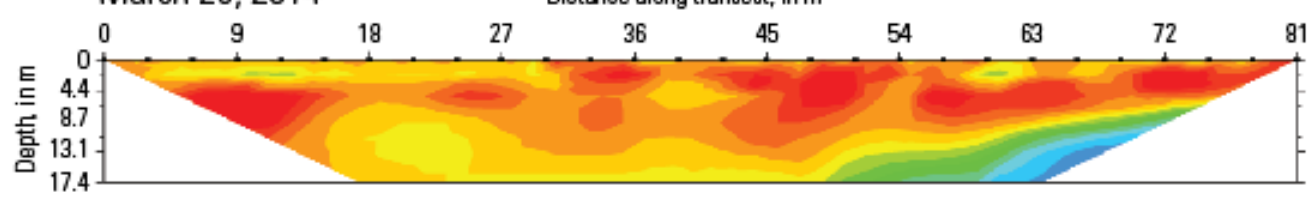

March 26, $2014 \quad$ Distance along transect, in $\mathrm{m}$

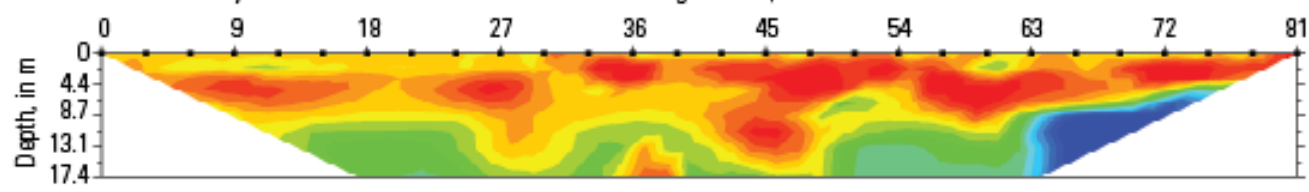

March 27, 2014 - Morning Distance along transect, in m

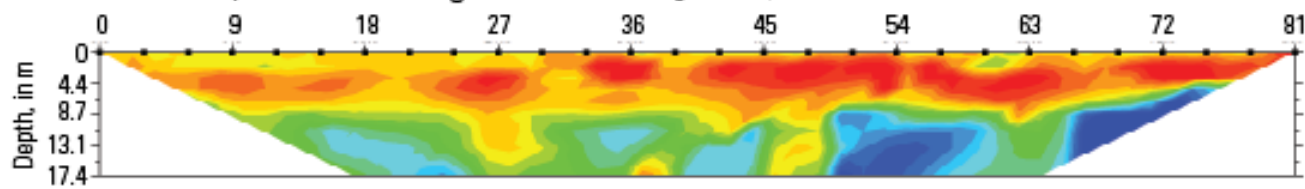

March 27, 2014 - Afternoon Distance along transect, in m
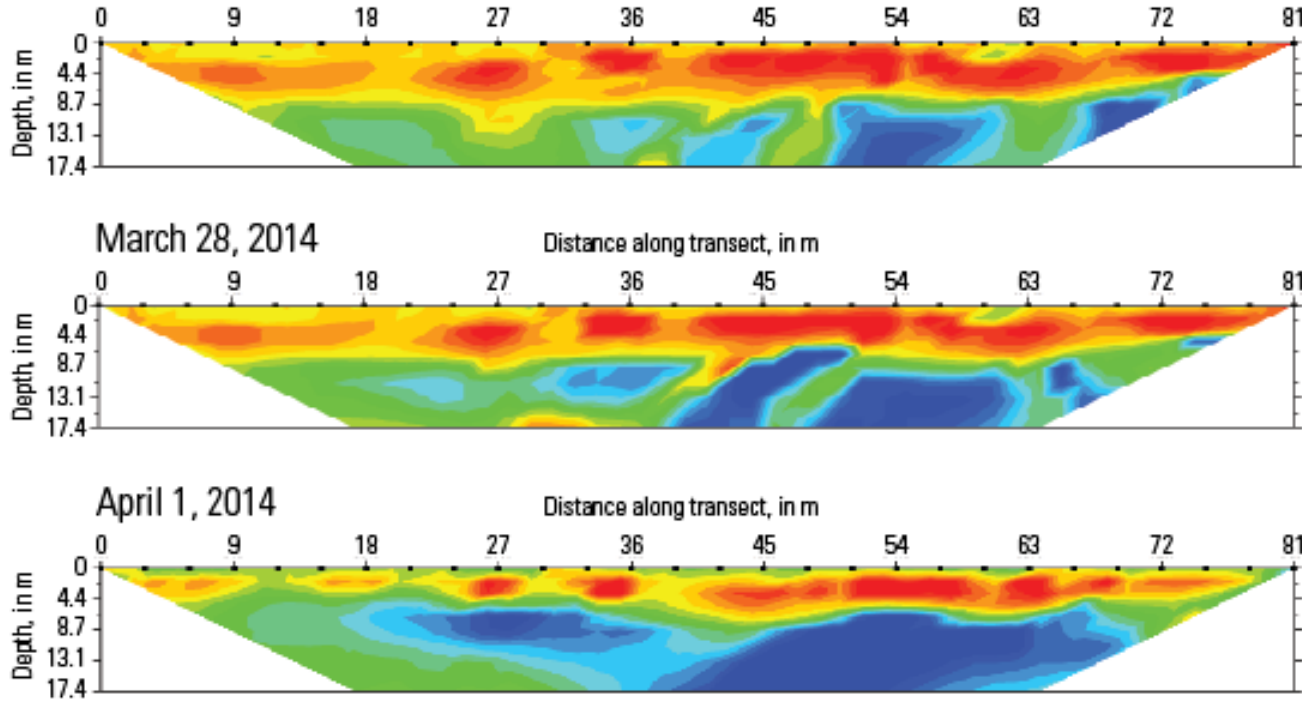

Resistivity, in ohm-m

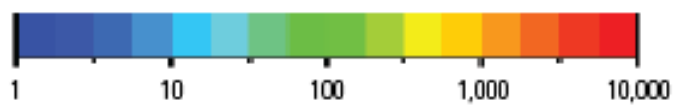

Figure 26. Cross sections showing apparent resistivity inversion of direct-current resistivity data at Transect 10, Colorado River, Arizona. m, meters; ohm-m, ohm-meters. 


\section{Transect 20}

S
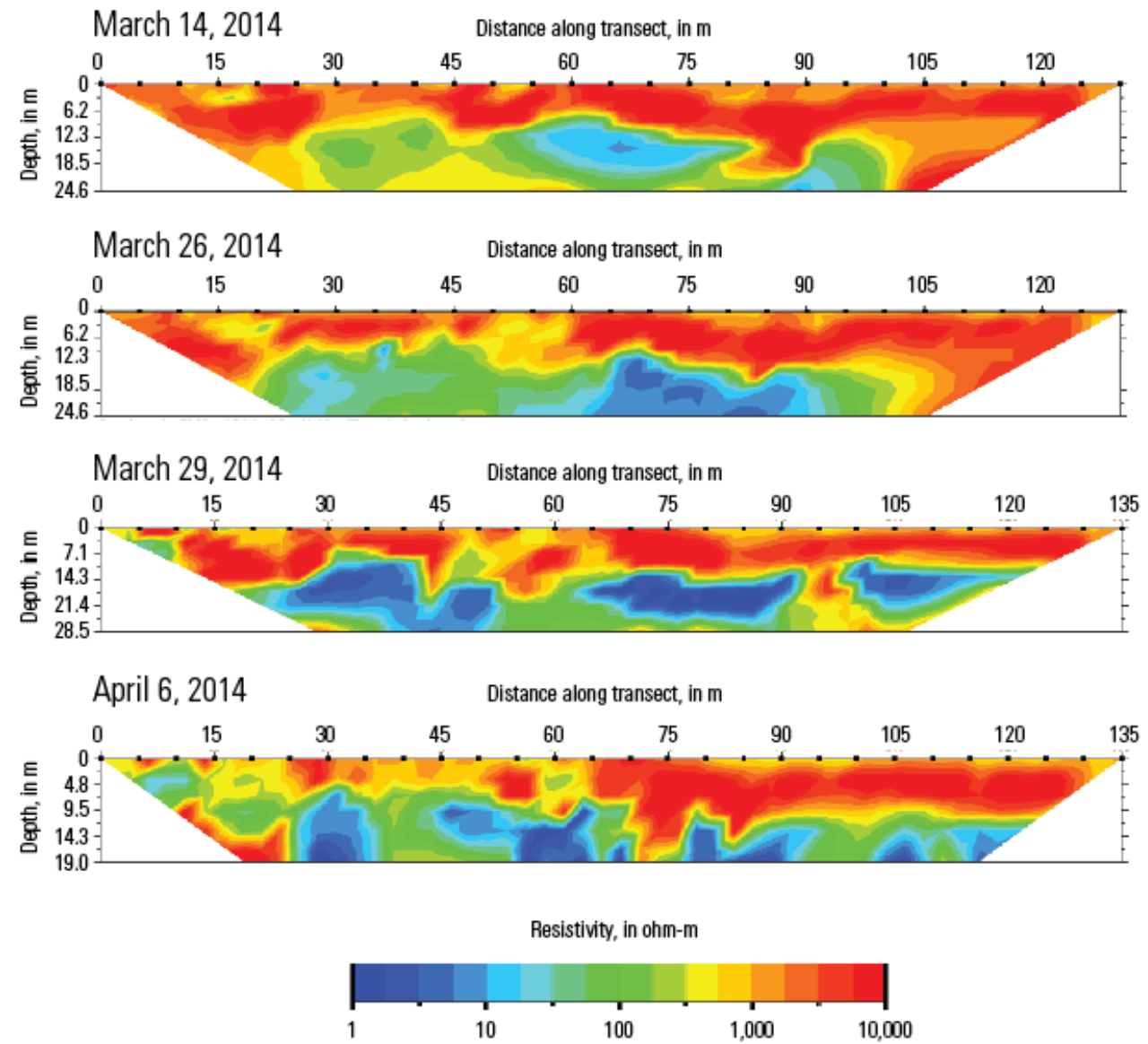

Figure 27. Cross sections showing apparent resistivity inversion of direct-current resistivity data at Transect 20, Colorado River, Mexico. m, meters; ohm-m, ohm-meters. 

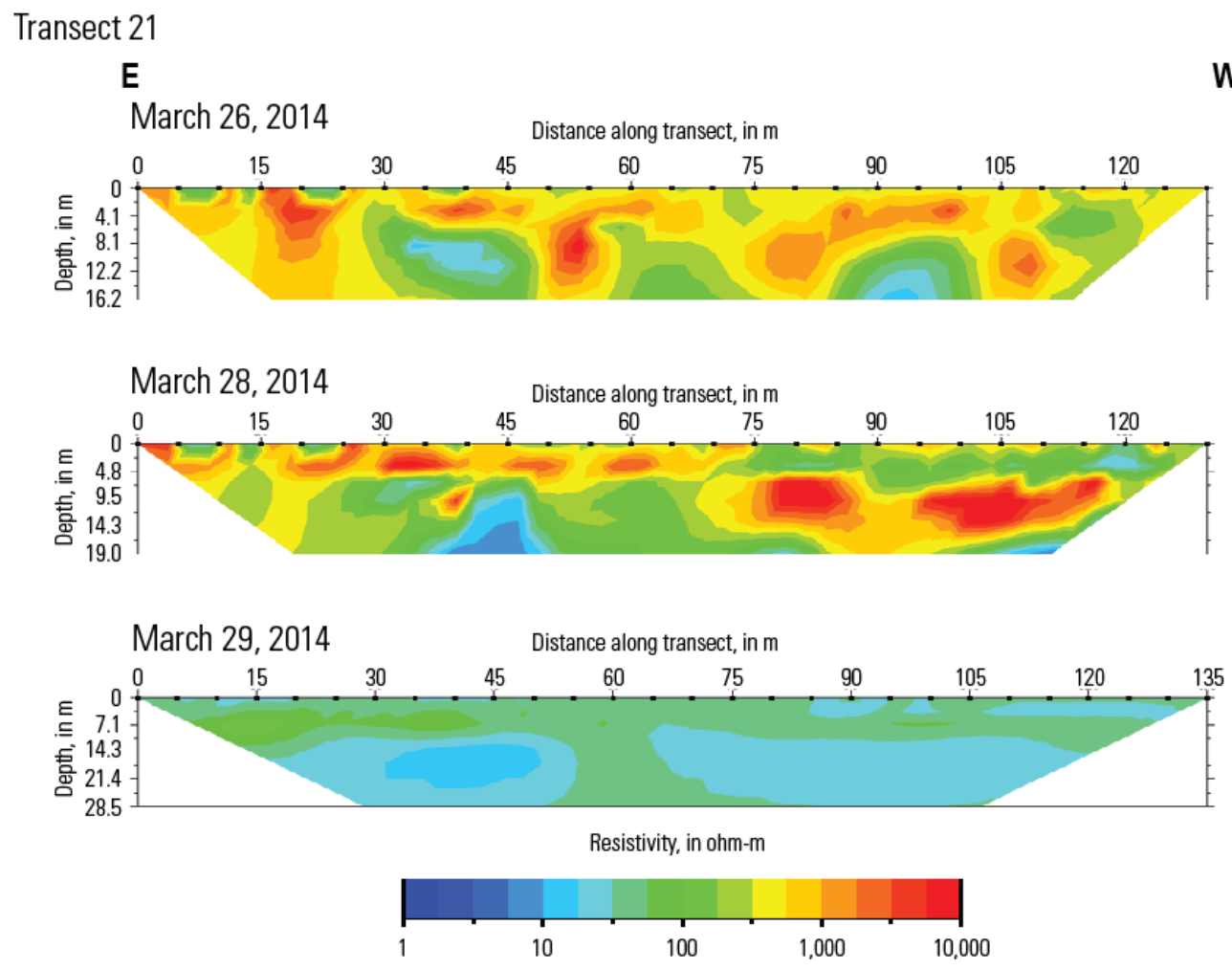

Figure 28. Cross sections showing apparent resistivity inversion of direct-current resistivity data at Transect 21 Colorado River, Mexico. m, meters; ohm-m, ohm-meters.

\section{Summary}

This Open-File Report and the accompanying Data Release (Kennedy and others, 2016a) present geophysical data collected to aid understanding of the hydrologic response to the 2014 pulse flow in the Colorado River delta. Gravity data and time-lapse resistivity data were collected to monitor the transient response of the subsurface to infiltrated water. Both of these can be used in developing and calibrating a groundwater-flow model. Gravity data, collected at 25 locations, provide a quantitative measurement of the change in aquifer storage. At four locations, gravity data combined with co-located water-level data provide an estimate of aquifer specific yield. Time-lapse resistivity data, collected at three transects, provide information about the depth of the water table and subsurface saturation prior to and during the pulse flow. Electromagnetic induction data collected prior to the pulse flow at 12 transects provide information about the spatial distribution of sedimentary material and subsurface heterogeneity of the study area. 


\section{References Cited}

Callegary, J.B., Leenhouts, J.M., Paretti, N.V, and Jones, C.A., 2007a, Rapid estimation of recharge potential in ephemeral-stream channels using electromagnetic methods, and measurements of channel and vegetation characteristics: Journal of Hydrology, v. 344, p. 1731.

Callegary, J.B., Ferré, T.P.A., and Groom, R.W., 2007b, Vertical spatial sensitivity and exploration depth of low-induction-number electromagnetic-induction instruments: Vadose Zone Journal, v. 6, p. 158-167.

Callegary, J.B., Ferré, T.P.A., and Groom, R.W., 2012, Three-dimensional sensitivity distribution and sample volume of low-induction-number electromagnetic-induction instruments: Soil Science Society of America Journal, v. 76, p. 85-91.

Dickinson, J.E., Land, M., Faunt, C.C., Leake, S.A., Reichard, E.G., Fleming, J.B., and Pool, D.R., 2006, Hydrogeologic framework refinement, ground-water flow and storage, waterchemistry analyses, and water-budget components of the Yuma area, southwestern Arizona and southeastern California: U.S. Geological Survey Scientific Investigations Report 20065135, 88 p., available at https://pubs.usgs.gov/sir/2006/5135/.

Everett, M.E., 2011, Theoretical Developments in Electromagnetic Induction Geophysics with Selected Applications in the Near Surface: Surveys in Geophysics, v. 33, no. 1, p. 29-63.

Hallof, P.G., 1992, Electrical - IP and Resistivity, in Van Blaricom, R., ed., Practical geophysics II for the exploration geologist: Spokane, Wash., Northwest Mining Association, $137 \mathrm{p}$.

Hwang, C., Wang, C., and Lee, L., 2002, Adjustment of relative gravity measurements using weighted and datum-free constraints: Computers and Geoscience, v. 28, p. 1005-1015.

International Boundary and Water Commission, 2014, Minute 319 Colorado River delta environmental flows monitoring: International Boundary and Water Commission, Initial Progress Report, 19 p., accessed September 8, 2016, at http://www.ibwc.gov/EMD/Min319Monitoring.pdf.

International Boundary and Water Commission, 2016. Minute 319 Colorado River limitrophe and delta environmental flows monitoring: International Boundary and Water Commission, Interim Report, 78 p., accessed September 8, 2016, at http://www.ibwc.state.gov/Files/Minutes\%20319/2016_EFM_InterimReport_Min319.pdf. Jarchow, C.J., Nagler, P.N., Glenn, E.P., Ramírez-Hernandez, J., and Rodríguez-Burgueño, E., 2016, Evapotranspiration by remote sensing - An analysis of the Colorado River delta before and after the Minute 319 pulse flow to Mexico: Ecological Engineering, http://dx.doi.org/10.1016/j.ecoleng.2016.10.056. [In press, corrected proof, available online October 18, 2016.]

Kennedy, J.R., 2015, Gravity data from the Sierra Vista Subwatershed, Upper San Pedro Basin, Arizona: U.S. Geological Survey Open-File Report 2015-1086, 26 p., https://dx.doi.org/10.3133/ofr20151086.

Kennedy, J.R., Callegary, J.B., Macy, J.P., Reyes-Lopez, J.A., and Pérez-Flores, M.A., 2016a, Geophysical Data Collected during the 2014 Minute 319 Pulse Flow: U.S. Geological Survey data release, http://dx.doi.org/10.5066/F7K935M8.

Kennedy, J.R., and Ferré, T.P.A., 2016, Accounting for time- and space-varying changes in the gravity field to improve the network adjustment of relative-gravity data: Geophysical Journal International, v. 204, p. 892-906, https://doi.org/10.1093/gji/ggv493. 
Kennedy, J.R., Koth, K.R., and Carruth, R.L., 2015, Surface and subsurface microgravity data in the vicinity of Sanford Underground Research Facility, Lead, South Dakota. U.S. Geological Survey Open-File Report 2015-1043, 32 p., http://dx.doi.org/10.3133/ofr20151043.

Kennedy, J., Rodríguez-Burgueño, E., and Ramírez-Hernández, J., 2016b, Groundwater response to the 2014 pulse flow in the Colorado River delta: Ecological Engineering, http://dx.doi.org/10.1016/j.ecoleng.2016.10.072. [In press, corrected proof, available online October 25, 2016.]

Knighton, A.D., 1980, Longitudinal changes in size and sorting of stream-bed material in four English rivers, Geological Society of America Bulletin, v. 91, p. 55-62, http://dx.doi.org/10.1130/0016-7606(1980)91<55:LCISAS>2.0.CO;2.

McNeill, J.D., 1980, Electrical conductivity of soils and rocks: Mississauga, Canada, Geonics Limited, Technichal Note TN-5, 22 p., accessed October 31, 2016 at http://geonics.com/html/technicalnotes.html.

Mueller, E.R., Schmidt, J.C., Topping, D.T., Shafroth, P.B., Rodríguez-Burgueño, J.E., RamírezHernández, J., Grams, P.E., 2016, Geomorphic change and sediment transport during a small artificial flood in a transformed post-dam delta - The Colorado River delta, United States and Mexico: Ecological Engineering, http://dx.doi.org/10.1016/j.ecoleng.2016.08.009. [In press, corrected proof, available online September 13, 2016.]

Nagy, D., 1966, The gravitational attraction of a right rectangular prism: Geophysics, v. 31, no. 2, p. 362-371.

Nelson, S.M., Ramírez-Hernández, J., Rodríguez-Burgueño, J.E., Milliken, J., Kennedy, J.R., Zamora-Arroyo, F., Schlatter, K., Santiago-Serrano, E., Carrera-Villa, E., 2016, A History of the 2014 Minute 319 environmental pulse flow as documented by satellite imagery: Ecological Engineering, http://dx.doi.org/10.1016/j.ecoleng.2016.10.040. [In press, corrected proof, available online October 21, 2016.]

Palacky, G.J., 1987, Resistivity characteristics of geologic targets, chap. 3 of Nabighian, M.N., ed., Electromagnetic methods in applied geophysics-Volume 1, Theory: Tulsa, Okla., Society of Exploration Geophysicists, Investigations in Geophysics no. 3, p. 53-129.

Olmsted, F.H., Loeltz, O.J., and Irelan, B., 1973, Geohydrology of the Yuma area, Arizona and California: U.S. Geological Survey Professional Paper 486-H, 226 p.

Pool, D.R., 2008, The utility of gravity and water-level monitoring at alluvial aquifer wells in southern Arizona: Geophysics, v. 73, p. WA49-WA59.

Pool, D.R., and Eychaner, J.H., 1995, Measurements of aquifer-storage change and specific yield using gravity surveys: Ground Water, v. 33, p. 425-432.

Revil, A., Karaoulis, M., Johnson, T., and Kemna, A., 2012, Review: Some low-frequency electrical methods for subsurface characterization and monitoring in hydrogeology: Hydrogeology Journal, v. 20, p. 617-658.

Schwendel, A.C., Nicholas, A.P., Aalto, R.E., Sambrook Smith, G.H., Buckley, S., 2015, Interaction between meander dynamics and floodplain heterogeneity in a large tropical sandbed river: Earth Surface Processes and Landforms: v. 40, p. 2026-2040, http://dx.doi.org/10.1002/esp.3777.

Sharma, P.V., 1997, Environmental and engineering geophysics: Cambridge, Cambridge University Press, 500 p.

Singer, M.B., 2008, Downstream patterns of bed material grain size in a large, lowland alluvial river subject to low sediment supply: Water Resources Research, v. 44, 7 p., http://dx.doi.org/10.1029/2008WR007183. 
Strang, G., and Borre, K., 1997, Linear Algebra, Geodesy, and GPS: Wellesley, Massachusetts, Wellesley-Cambridge Press, 624 p.

Torge, W., 1989, Gravimetry: Berlin, De Gruyter, 465 p.

Touati, F., Kahlouche, S., and Idres, M., 2010, Robust and efficient weighted least squares adjustment of relative gravity data, in Mertikas, S.P., ed., Gravity, Geoid, and Earth Observation, International Association of Geodesy Symposia: Berlin, Springer-Verlag Berlin Heidelberg, p. 59-65.

Walling, D.E., and He, Q., 1998, The spatial variability of overbank sedimentation on river floodplains: Geomorphology, v. 24, p. 209-223.

Zohdy, A.A.R., Eaton, G.P., and Mabey, D.R., 1974, Application of surface geophysics to ground-water investigations: U.S. Geological Survey Techniques of Water-Resources Investigations, book 2, chap. D1, $116 \mathrm{p}$. 


\section{Appendix 1. Electronic Data Files}

The following files are hosted on Sciencebase as part of an accompanying data release (Kennedy and others, 2016a; http://dx.doi.org/10.5066/F7K935M8). In addition, USGS data are archived at the Arizona Water Science Center according to the Center's surface geophysics data quality assurance plan.

1. Gravity Data

a. Raw gravity data, drift-corrected relative-gravity differences ("dg.txt" extension), and absolute-gravity data ("fix.txt" extension).

i. 2014_Minute319_raw.zip

1. 2014-03-11_Minute319.txt

2. 2014-03-12 Minute319.txt

3. 2014-03-18 Minute319.txt

4. 2014-03-19_Minute319.txt

5. 2014-04-01_Minute319.txt

6. 2014-04-02_Minute319.txt

7. 2014-04-03_Minute319.txt

8. 2014-04-21 Minute319.txt

9. 2014-04-22_Minute319.txt

10. 2014-04-23_Minute319.txt

11.2014-04-24_Minute319.txt

ii. 2014_Minute319_network_adjustment_dg.zip

1. 2014-03_Minute319_dg.txt

2. 2014-4a_Minute319_dg.txt

3. 2014-4b_Minute319_dg.txt

iii. 2014_Minute319_network_adjustment_fix.zip

1. 2014-03_Minute319 fix.txt

2. 2014-04a Minute319 fix.txt

3. 2014-04b_Minute319_fix.txt

b. Summary of results

i. (2014_Minute_319_gravity_tabular_data.xlsx). Worksheets:

1. Adjusted gravity values

2. Direct attraction (of water ponded in channel)

3. Specific yield

4. Adjustment notes

ii. Shapefile (2014_Minute_319_gravity_point_data.zip)

2. Electromagnetic induction data

a. Data file

(2014_Minute_319_electromagnetic_induction_tabular_data.xlsx). One worksheet per transect.

b. Metadata

(2014_Minute_319_electromagnetic_induction_tabular_data.xml)

c. Shapefile (2014_Minute_319_electromagnetic_induction.zip)

3. Direct-current resistivity data 
a. Raw data files from Advanced Geosciences Inc. Sting/Swift R1 (2014_Minute_319_DC_resitivity_tabular_data.zip). File naming convention is $\mathrm{tNN}_{-} \mathrm{YYY} \bar{Y} \mathrm{Y}-\mathrm{MM}-\mathrm{DD}$.dat, where $\mathrm{NN}=$ transect number, $\mathrm{YYYY}=$ year, $\mathrm{MM}=$ month, and DD = day.

i. t10_2014-03-23.dat

ii. t10 2014-03-25am.dat

iii. t10 2014-03-26am.dat

iv. t10 2014-03-27am.dat

v. t10_2014-03-27pm.dat

vi. t10_2014-03-28.dat

vii. t10_2014-04-01.dat

viii. t20 2014-03-14.dat

ix. t20_2014-03-26.dat

x. t20_2014-03-29.dat

xi. t20_2014-04-06.dat

xii. t21_2014-03-26.dat

xiii. t21_2014-03-28.dat

xiv. t21_2014-03-29.dat

b. Metadata (2014_Minute_319_DC_resitivity_tabular_data.xml)

c. Shapefile (2014_Minute_319_DC_resitivity_vector_data.zip) 
ISSN 2331-1258 (online)

https://doi.org/10.31

20171050 